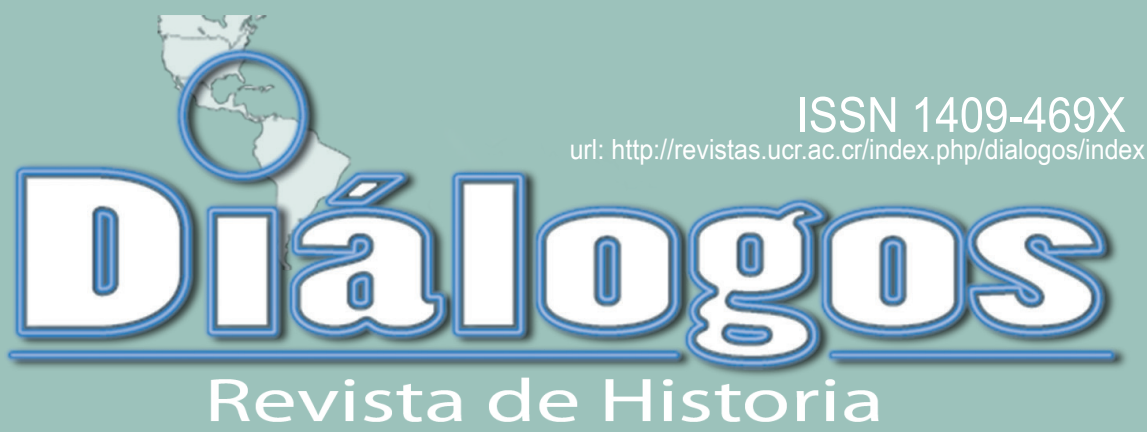

Escuela de Historia. Universidad de Costa Rica Vol. 15 No. 2 Setiembre 2014 - Enero 2015

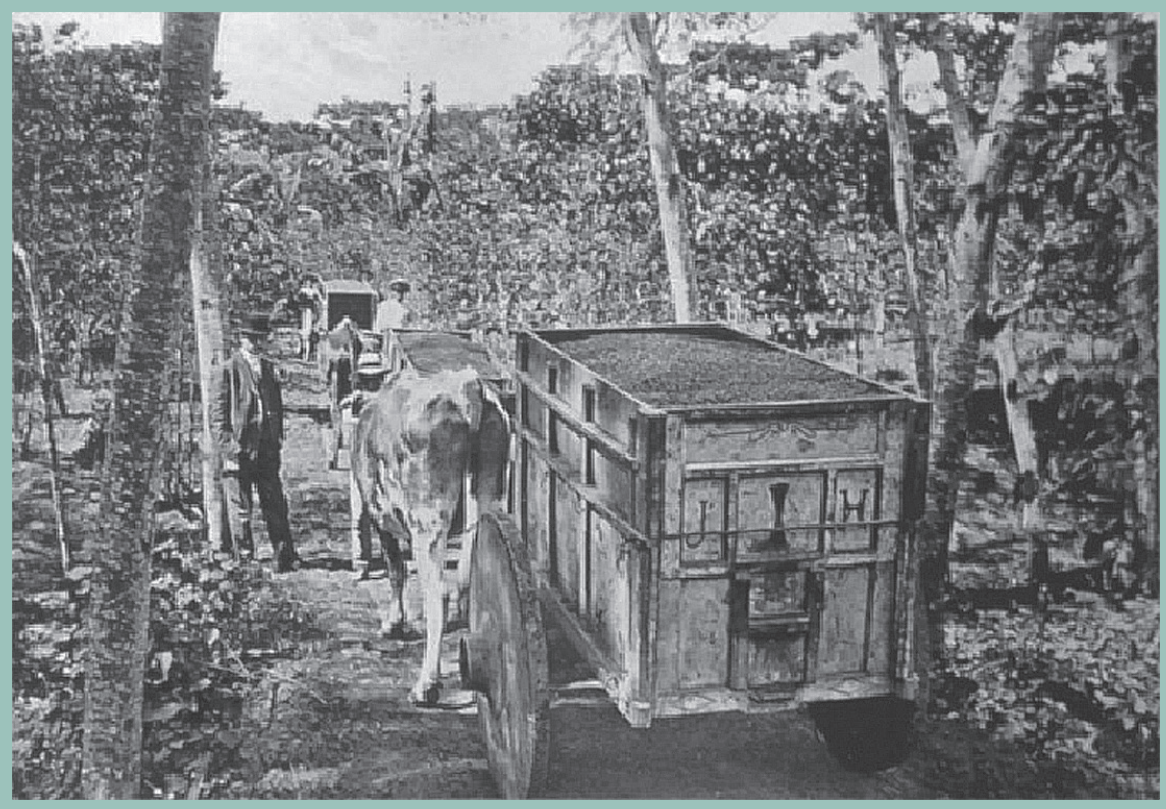

Director de la Revista: Dr. Juan José Marín Hernández juan.marinhernandez@ucr.ac.cr

Editor académico: Dr. David Díaz Arias - david.diaz@ucr.ac.cr Editor técnico: M.Sc. Marcela Quirós G. - marcela.quiros@ucr.ac.cr

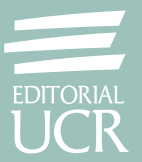


SECCIÓN COSTA RICA 


\title{
UNA CONTRIBUCIÓN AL ESTUDIO DE LA MICROHISTORIA: CURRIDABAT, SU PAISAJE CAFETALERO Y LA RECONSTRUCCIÓN DEL TEMPLO CATÓLICO, 1850-1950
}

\section{CURRIDABAT: A CONTRIBUTION TO THE STUDY OF MICROHISTORY. 1850-1950, RECONSTRUCTION OF THE CATHOLIC CHURCH}

\author{
Jorge Marchena Sanabria
}

\begin{abstract}
Palabras claves
Historia, microhistoria, Ciencias Sociales, Curridabat, paisajes, café, catolicismo, urbanización.

Keywords

History, microhistory, Social Sciences, Curridabat, landscapes, coffee, Catholicism, urbanization.

Fecha de recepción: 30 de julio, 2013 - Fecha de aceptación: 22 de abril 2014

Resumen

La presente investigación se concentra en analizar el desarrollo de la comunidad de Curridabat durante la primera mitad del siglo XX, a partir de una perspectiva vinculada a la microhistoria y tomando en cuenta algunos postulados de la geografía histórica. De este modo, los tres ejes centrales son la caracterización del paisaje cantonal, la presencia medular del cultivo café y la influencia que tuvo la reconstrucción del templo católico. Esto último, influyó en cierto grado, a estimular el proceso de urbanización que se daría en las siguientes décadas; pues el inmueble funcionó como un punto de referencia para las identidades locales.
\end{abstract}

\begin{abstract}
This research focuses on analyzing the development of the Curridabat community during the first half of the twentieth century, from a perspective linked to the micro-history and taking into account some assumptions of historical geography. Thus, the three central themes are the cantonal landscape characterization; the influence of the coffee crops and the rebuilding of the Catholic Church. The latter influenced to some degree, to stimulate the process of urbanization that would occur in the next decades, for the building functioned as a benchmark for local identities.
\end{abstract}




\section{PLANTEAMIENTOS ESENCIALES 1}

Es notoria la abundancia de publicaciones en torno a la historia comunal de los distintos barrios y cantones de Costa Rica. Los bazares, supermercados locales y las bibliotecas públicas ofrecen una amplia gama de obras que, como patrón generalizado, exaltan las identidades locales, los mitos, las anécdotas, los personajes célebres y una serie de cronologías que sobredimensionan nuestra realidad social e histórica. Más que cuestionar o peor aún, rechazar estas obras, que por cierto, son muestra del interés cotidiano por reconstruir la historia y rescatar la memoria colectiva; la tarea de los historiadores de profesión es contribuir a generar y fortalecer el conocimiento de estas mismas localidades, y relegar en la medida de lo posible idealizaciones y visiones maniqueas y románticas; así como tratar de buscar sustento en un mayor abanico de fuentes y de herramientas teórico-metodológicas propias de las Ciencias Sociales.

Es importante resaltar que en diversas fuentes se hace referencia a la antigua Curridabat -en la primera mitad del siglo XX- como un mundo idílico, descrito como un "caserío de tejas y adobes que rodeaba la vieja y polvorienta plaza de ayer" (Batista, 1993), o como un pueblo de empedradas calles, cuadrantes exactos, carruajes, alumbrado por medio de candelas y "fincas con fantasmas", pozas limpias en el María Aguilar y el Tiribí. Es claro que se resaltaba la mítica frescura y pasividad en Curridabat (Madrigal, 1974, p.53). Después de 1940, se consideró que Curridabat se había transformado de una villa marginada a un prototipo de ciudad, por lo cual, el mundo rural adoptó diversos elementos de urbe moderna: se pavimentaron las calles (con piedra triturada: macadamización), se alinearon cuadras, aparecieron talleres e industrias, las redes municipales se extendieron, se establecieron oficinas de correos, telégrafos, periódicos y teléfonos, entre otros. Es tarea fundamental de la presente investigación entender a fondo estos cambios,

De esta forma, se pretende construir una visión preliminar en torno a dos temas que parecen disímiles, pero que consideramos son perfectamente complementarios: el desarrollo y consolidación de la actividad cafetalera en Curridabat y la reconstrucción del templo católico, como base para la creación de un centro urbano; el que tendría la función de articular el sistema productivo afín al modelo agroexportador. El periodo de estudio se extiende principalmente en la primera mitad del siglo XX y toma en cuenta las décadas precedentes y subsecuentes. ${ }^{2}$ Además, abarca un área geográfica que incluye los límites del actual cantón, aunque se trata de mantener correlaciones con otras localidades vecinas y la gran influencia que ejerció la ciudad de San José, como eje medular de sus dinámicas políticas y económicas. 
El problema de investigación se sitúa en la necesidad de comprender cómo pequeñas localidades rurales fueron integradas dentro de mayores regiones agrarias con énfasis cafetalero, y a la vez, la función que cumplieron en la expansión y consolidación del sistema agroexportador-liberal durante la primera mitad del siglo XX. Un segundo aspecto a estudiar es la relación que existió entre la construcción de templos modernos para el culto católico y la consolidación de urbes o centros productivos propios del mundo cafetalero.

Nuestro argumento central precisa que la comunidad de Curridabat era una población de larga data, caracterizada por caseríos dispersos, similar a otros existentes en la Meseta Central hasta por lo menos la primera mitad del siglo XIX. Diversas obras han clarificado que el café cambió radicalmente las dinámicas productivas e integró al naciente país dentro de la lógica capitalista mundial, a través de las exportaciones cafetaleras y sus nuevos nexos con las metrópolis transcontinentales. En el caso concreto de la zona que analizada, fue absorbida por el café y durante más de un siglo este producto se convirtió en la actividad económica predominante.

No obstante, en un primer momento, el futuro cantón simplemente experimentó el nacimiento de múltiples fincas del grano y mantuvo una escasa población. Una segunda fase comenzó, aproximadamente, a partir del último decenio del siglo XIX, como consecuencia de la instalación del tendido ferroviario en los linderos del lugar. A partir de ello, se constituyó un paisaje esencialmente agrario con preeminencia del café y su propia infraestructura: beneficios, caminos, etc.; sumado al nacimiento de un incipiente centro semi-urbano o más bien, un punto de control administrativo-productivo.

Como más adelante se detalla, la expansión urbana y política de la ciudad de San José, así como el mismo desarrollo cafetalero, conllevaron la formación de una estructura socioeconómica más compleja e impidieron que las nuevas zonas integradas a la producción cafetalera tuvieran un control directo, por parte de la capital. Para ello, a principios del siglo XX y en las décadas siguientes, se hizo necesario fundar pequeñas subsidiarias de este poder central. En otras palabras, los nuevos cantones que surgen o se consolidan en estos años son los representantes de la autoridad nacional e indirectamente, de los potentados cafetaleros, ávidos por mantener la estabilidad y el buen funcionamiento del universo agroexportador.

En consecuencia, la reconstrucción de un templo católico contribuía en esta dirección, pero más que orientarse al mero control social ${ }^{3}$ y de las almas, la infraestructura religiosa se convertiría, por sus dimensiones y fastuosidad, en una especie de geosímbolo. Este último se reconoce como un rasgo destacado del paisaje, también puede ser un cerro, una plaza o un edificio cualquiera; que posee una carga simbólica y ayuda a articular la historia de una comunidad o su identidad. 
Aprovechando la antigüedad relativa de la parroquia, el predominio ideológico que la iglesia católica mantuvo a lo largo del siglo XIX y la notoriedad que un edificio eclesiástico intrínsecamente inviste (su majestuosidad); se pudo constituir un pilar o punto de partida para levantar la urbe, la cual tenía, anexa a la iglesia, también la plaza, la escuela y los inmuebles que daban albergue a la Municipalidad. En síntesis, el templo fue un incentivo para atraer a los pobladores, concentrarlos en una zona específica y a partir de ello, seducirlos para que fueran fieles ciudadanos y miembros activos del mundo cafetalero.

Las fuentes de este artículo fueron diversas, principalmente constituidas por documentos del Archivo Histórico Arquidiocesano Bernardo Augusto Thiel (AHABAT) y el Archivo Nacional (ANCR), así como notas periodísticas, censos agrícolas y una serie de bibliografía afín a la temática. La metodología predominante estuvo familiarizada con la geografía histórica y su énfasis en la reconstrucción de paisajes pretéritos. ${ }^{4}$ Aunado a esto, se trató, en la medida de lo posible, abocarse a los planteamientos de la microhistoria propuesta por Giovanni Levi y en general, de una historia social entretejida con las comunidades.

Y es que la microhistoria es una herramienta esencial, no para destacar los idealismos de la historia local, sino para trabajar en escalas más reducidas de análisis. Básicamente, esta rama historiográfica no se limita al análisis de lugares pequeños, sino que extrapola las problemáticas de investigación empleadas en regiones grandes a espacios más reducidos, y lejos de simplificar los estudios, lo que pretende es lograr una exploración más detallada, así como revisar minuciosamente el impacto de procesos históricos estructurales en estos espacios. Otra forma de concebir a la microhistoria es como "una observación microscópica que revelará factores anteriormente no observados" (Levi, 1996, pp. 119-124).

Como consecuencia del auge de la microhistoria, especialmente la propuesta por Levi (1996), se consolidaron en las últimas décadas tres grandes tendencias que vale la pena citar: el estudio de pueblos, el rescate de "personajes olvidados" y las investigaciones centradas en las familias. Cualquiera que fuese la opción a seguir, los análisis no deben caer en extremos, es decir, no se debe escribir con énfasis solo en los lugareños (esto puede convertir el trabajo en irrelevante para actores externos), pero tampoco se debe llegar a conclusiones únicamente en función de los procesos globales o de mayor escala; pues esto producirá estudios inaccesibles para un lector medio. ${ }^{5}$

Otro punto a destacar, lo propone el historiador Iván Molina Jiménez (2000, pp. 1-5), quien también apunta que con la microhistoria no se intenta estudiar lugares aislados o tratar de encontrar absurdas y casi míticas excepcionalidades, ni generar monografías excesivamente descriptivas. Al contrario, se debe mantener el diálogo abierto con regiones o zonas más grandes y comprender el grado de integración 
que los pueblos tenían con éstas, creando nexos entre aspectos políticos, culturales y económicos afines.

Por último, esta disertación se divide en tres grandes secciones: la presente repasa los elementos fundamentales que guían el trabajo de investigación, la segunda se concentra en los cambios en el paisaje rural del cantón, la consolidación del modelo agroexportador y el predominio del café como mecanismo articulador de las dinámicas político-económicas y el tercer apartado se enfoca en la (re) construcción del templo y su relación con el aparato productivo local.

\section{EL PAISAJE DE CURRIDABAT EN LA PRIMERA MITAD DEL SIGLO XX}

\section{Generalidades del cantón de Curridabat y la fundación del pueblo primigenio}

Administrativamente, Curridabat se constituyó como un pueblo de San José, además, a lo largo del siglo XIX se le vinculaba con Aserrí y Desamparados. A inicios del siglo XX, todavía era un distrito josefino, hasta su posterior ascenso como el cantón $\mathrm{N}^{\circ} 18$ de la provincia de San José, en 1929. Se encuentra dividido en cuatro unidades distritales: Curridabat, Granadilla, Sánchez y Tirrases; abarcando un área de $15.95 \mathrm{~km}^{2}$ y para el año 2011 contaba con una población de 65.206 habitantes (Instituto Nacional de Estadísticas y Censos, 2011). Geológicamente, está conformado por rocas de origen volcánico y sedimentario y la mayor parte del cantón se localiza en una superficie plana ondulada. La región, a su vez, se encuentra influenciada por el Volcán Irazú; presenta laderas y diversas pendientes. $\mathrm{Su}$ altitud promedio es de 1.200 metros sobre el nivel del mar. Los ríos de la zona forman parte de la cuenca del Río Grande de Tárcoles, drenado por los ríos María Aguilar y Tiribí y las quebradas Zopilote, Mina y Poró surgen en la localidad (véase el Mapa $\mathrm{N}^{\circ} 1$ en los Anexos). La temperatura promedio es de 20,6 y la precipitación de $2.000 \mathrm{~mm}$ anuales, aproximadamente (Municipalidad de Curridabat, 2003, p. 34), (Instituto Fomento y Asesoría Municipal, 1987, p. 90).

Antes de la llegada de los europeos, el territorio estuvo ocupado por poblaciones autóctonas. El otrora cacicazgo de Curridabat era uno de los más importantes del Valle Central, zona que se caracterizaba en el siglo XVI por el predominio de las actividades agrarias (maíz y pejibaye), y por viviendas dispersas; aunque probablemente existiera un centro de control político-religioso, cuyo eje de vida social giraba en torno a una plaza central. Esta misma locación se mantenía vinculada a las de Aserrí, Pacaca y Coto; mientras que sostenía múltiples conflictos bélicos con las del Pacífico Sur (Ibarra, 2002, pp. 41 y 51-55). Precisamente, a este pasado indígena debe su nombre 
el actual cantón, pues Curridabat o Curriravá, como también se le conoció en tiempos coloniales, es una variante del nombre de un cacique local (Sandí, 2011, p. 55).

Pocos datos se han rescatado de este período y la mayoría caen más en curiosidades que en información verdaderamente valiosa, que esclarezca la cultura y desarrollo de estas sociedades. Aparentemente, el lugar, antes de la invasión española, se denominaba Porrrosquirris y estaba gobernado por el cacique Corrirabá (Diario de Costa Rica, 1961, p. 4). Otras referencias afirman que Curi-Aba era una palabra azteca utilizada por los huetares y chorotegas, mientras que el cacique Curriravá era un "gran amigo" de Vázquez Coronado (Portilla, 1979, p. 7).

Las anteriores reseñas exaltan la llegada de los europeos y se afirma implícitamente que los pobladores se alegraron y sometieron de buen gusto a los recién llegados, esto minimiza aspectos más importantes. Tales como la imposición de tributos y encomiendas, así como otras enajenaciones que sufrió la población local. Precisamente, entre 1564 y 1568, múltiples asentamientos autóctonos se levantaron violentamente contra el emplazamiento español de Cartago; entre las fuerzas rebeldes se encontraban: Aserrí, Orosí, Ujarrás y Curridabat, entre otros (Ornat, s.f.). Tras su derrota los nativos fueron encomendados a Don Antonio Pereyra. Según los registros, éste recibió cerca de 600 personas (Thiel, 1983, p. 13). La visión de una conquista pacífica y sin resistencia es imprecisa y carente de fundamentos sólidos.

Comúnmente, se ha establecido que el poblado españolizado se fundó en el siglo XVI, cerca de 1570 ó 1580, sin una fecha más específica, además lo más preciso fue que se otorgaron indígenas en encomienda, no que se construyó una ciudadela claramente demarcada. Derivado de lo anterior, también se considera que la parroquia de Curridabat data de 1575 (una de las primeras del interior de Costa Rica) y así lo atestigua el sello y la documentación actual de la misma; por el contrario, el material consultado precisa que dicha condición se le otorgó hasta el siglo XIX y que antes de esa época solo era una doctrina en conjunto con Aserrí.

Esto se relaciona, a su vez, con las dificultades para definir con exactitud la localización del poblado. Al considerarlo estrictamente como un territorio indígena, éste no se ubicó, necesariamente, en el actual emplazamiento del distrito central, puesto que los asentamientos autóctonos también abarcaban los cantones contemporáneos de Tres Ríos, Aserrí y Montes de Oca. Por otro lado, el pueblo colonial fue un emplazamiento "errante" que se trasladaba de una posición a otra, probablemente por la necesidad de acercarse a Cartago o por problemas con el medio: buscar alimentos, fuentes de agua, etc. ${ }^{6}$ Asimismo, la iglesia o ermita era una edificación también "nómada", que se ubicó cerca del actual Tres Ríos, en el norte de Curridabat (cerca del distrito de Cipreses) y por último, en su actual emplazamiento; cuántos templos hubo y dónde se ubicaron no son aspectos que se puedan definir de manera concluyente. ${ }^{7}$ 
Cabe agregar, que durante el siglo XVIII, la población apenas superaba el centenar de habitantes, constituido por blancos, indígenas, mestizos y mulatos. En 1752 se le describía como un llano "montuoso", con una sencilla iglesia, edificaciones de teja, cuatro calles y poco más de treinta familias (Rodríguez, 1998, p. 35). A lo largo del siglo XIX, se mantuvo como un territorio básicamente rural, en el cual se introdujo el cultivo del café a mediados de siglo. La población para el año 1844, según lo documentó Monseñor Bernardo Augusto Thiel, era de tan solo 365 habitantes; pero suficientes como para sostener una escuela, municipios temporales y otras dependencias a lo largo de estos decenios.

También es importante anotar que entre 1830 y 1840, el naciente Estado costarricense afín a un sistema patriarcal-oligárquico y con claras simpatías hacia la burguesía cafetalera que tomaba forma, había comenzado sus ataques en contra de los pueblos y cabildos indígenas, con la finalidad de apoderarse de esas tierras (a las que declaraban como "baldíos ociosos") y dedicarlas al nuevo cultivo. Pocos años más tarde la arremetida fue más enérgica y se privatizaron las antiguas tierras comunales, pueblos como Tres Ríos, Barva y Curridabat fueron parcialmente desestructurados y sus tierras luego fueron transferidas a los ladinos (Ibarra, 1999, pp. 99-100). Si observamos el Cuadro $\mathrm{N}^{\circ} 1$, para la década de 1860 se presentó un notorio repunte demográfico. Esto permite intuir que dicho aumento se debió a un nuevo influjo migratorio que llegó a Curridabat, dispuesto a expandir los cafetales tras el desplazamiento de los indígenas.

Es claro lo antes mencionado, puesto que en 1860 hay un aumento destacable de la población, aunque ésta se mantendría estable en las últimas décadas y es hasta el siguiente siglo, que se podrá observar una nueva alza. Igualmente, se puede apreciar que el auge demográfico se patentiza a partir de 1950, posiblemente como efecto de los progresos en salud pública, especialmente en los rubros de natalidad y mortalidad. El salto cuantitativo observado en los setentas (cuando la población superó los quince mil habitantes) se presupone como fruto del proceso de urbanización y de la atracción de migrantes hacia el cantón por su cercanía a la capital. Esto mismo dio como resultado, la constitución de la localidad como un cantóndormitorio periférico a la ciudad de San José, a finales del siglo pasado.

De esta forma, la Tabla 1 muestra en detalle la población del cantón, de acuerdo con los censos disponibles.

\section{El marco contextual de los cantones periféricos josefinos del este}

Curridabat es parte fundamental de un sistema de cantones ubicados en el eje noreste de la ciudad de San José, entre estos se encuentran: Montes de Oca (otrora conocido como San Pedro del Mojón), Guadalupe-Goicoechea, Moravia, Aserrí, 
e incluso tiene ciertos ligámenes con secciones del cantón de Desamparados y de La Unión de Tres Ríos, perteneciente éste último a la provincia de Cartago. Estos departamentos político-administrativos eran parte del anillo rural de la ciudad de San José desde mediados del siglo XIX y hasta las últimas décadas del XX; hoy son cantones con funciones residenciales, comerciales e industriales, que conforman la Gran Área Metropolitana. Para comprender más a fondo estas regiones -y a Curridabat en particular-, es menester revisar el desarrollo del casco capitalino.

\section{Tabla 1}

POBLACIÓN DEL CANTÓN DE CURRIDABAT POR GÉNERO

ENTRE 1844 Y 2011

\begin{tabular}{rrrr}
\hline AÑO & HOMBRES & MUJERES & \multicolumn{1}{c}{ TOTAL } \\
\hline 1844 & $\ldots \ldots$ & $\ldots \ldots$ & 365 \\
1864 & $\ldots \ldots$ & $\ldots \ldots$ & 1.206 \\
1883 & 577 & 650 & 1.227 \\
1892 & 957 & 973 & 1.930 \\
1927 & $\ldots \ldots$ & $\ldots \ldots$ & 2.551 \\
1950 & 2.187 & 2.310 & 4.497 \\
1963 & 4.641 & 4.850 & 9.491 \\
1973 & 7.653 & 7.938 & 15.591 \\
1984 & 15.323 & 16.631 & 31.954 \\
2000 & 29.367 & 31.522 & 60.889 \\
2011 & 30.590 & 34.616 & 65.206 \\
\hline
\end{tabular}

Nota: Elaborado a partir de datos datos del Instituto nacional de estadísticas y censos de Costa Rica y Centro centroamericano de población Costa Rica.

La decimonónica ciudad de San José, específicamente en las últimas tres décadas, distaba mucho de ser precisamente una urbe. En primera instancia, era un pueblo de dimensiones reducidas, que se extendía desde la Sabana en el oeste hasta un poco más allá de la Estación del Atlántico en el este, su límite sur era cercano a la Iglesia de La Dolorosa y el norte, otro templo, el del Carmen. Superados estos límites se alternaban los cafetales y los potreros; en otras palabras, era una comunidad claramente separada de sus vecinas, las ciudades de Heredia, Alajuela y la aún más lejana, Cartago. 
A partir de 1880, con la modernización que experimentó el casco urbano, motivado por la ideología de progreso material de los liberales, San José comenzó a dar albergue a una nueva infraestructura pública: la estación del ferrocarril, plazas, biblioteca, alumbrado eléctrico, cañerías, edificio de correos y telégrafo, entre otros. Paralelo a este proceso, la ciudad se convirtió en el centro de control político, comercial y de relaciones internacionales; además de foco educativo y cultural.

San José concentraba la mayor parte de la población y a su alrededor pulularon las pequeñas villas, con una escasa población, ínfimos servicios y contando, a lo sumo, con una iglesia y una escuela. Estas periferias agrícolas, que se ubicaban en un radio de varios kilómetros con respecto al casco urbano de San José, estaban integradas, principalmente, de acuerdo con dos lógicas del sistema liberal: una era que funcionaban como abastecedores del pequeño mercado interno, es decir de alimentos. Ejemplos de esta especialización rudimentaria fueron Puriscal, en el sur, que abastecía de granos, o Santo Domingo de Heredia, en el norte, que a finales del siglo XIX todavía contaba con milpas para al autoconsumo. La otra dinámica, que siguieron gran parte de estas zonas rurales, era proveer del producto más importante que se cultivaba en la Meseta Central: el café.

Siguiendo esta misma argumentación, la capital era el centro administrativo del comercio exterior del llamado "grano de oro", en especial cuando daba asiento a los bancos que financiaban la actividad, a parte de la élite dueña de las fincas más grandes o de los beneficios que procesaban el café y al gobierno que supervisaba el buen desempeño de este sistema agroexportador. A sus alrededores se desarrollaban, lógicamente, las zonas productoras. Estas localidades, como ya se mencionó, no contaban con infraestructura básica, era difícil observar cañerías, edificios públicos o afines, ni mercados grandes; a lo sumo pequeñas pulperías para el abastecimiento de ciertos productos, aunque esto último se dio en las villas más importantes.

Ante una observación más detenida, estos minifundios de café, antes de la modernización agrícola (intensificada después de 1950), contaban con secciones dedicadas al pastoreo, con especial énfasis en la extracción de lácteos (leche y quesos), caña de azúcar, zonas para milpas, matas de guineo, árboles frutales y áreas para animales de granja (cerdos y gallinas). Estas unidades productivas cumplían dos funciones: abastecer de café y a la vez, suplir a las familias campesinas. Estas eran sociedades pre-capitalistas, en las cuales no imperaba el trabajo asalariado, más bien, dada la escasa población costarricense, dependían de la mano de obra familiar para las distintas tareas del café: limpieza, recolección, clasificación y luego acarreo a los beneficios. Dado que el cultivo era marcadamente estacional (una sola cosecha anual), el resto del año debía dedicarse al agro para la manutención básica y a lo sumo, intercambiar productos excedentarios con otras unidades familiares similares. 
En muchos casos, incluyendo a zonas cafetaleras como La Uruca, Pavas, San Pedro y por supuesto, Curridabat; lo indispensable o determinante fue la construcción de la línea férrea, el establecimiento de los beneficios y la apertura de puentes o caminos, que facilitaran la extracción de los sacos de café. Debe hacerse hincapié en que muchos de los actuales cantones de San José, en especial los ya mencionados, se encontraban muy cerca o fueron atravesados por el tendido del ferrocarril. ${ }^{8}$ Precisamente, la ruta del tren que se comenzó a trazar durante la dictadura de Tomás Guardia, en el decenio de 1870, recorría las principales fincas cafetaleras de la Meseta Central, desde Alajuela hasta Cartago y conectaba las propiedades de familias de la llamada "oligarquía cafetalera", lo que favorecía el surgimiento de nuevas haciendas; todo con miras a facilitar la salida del grano hacia el Atlántico y de allí, a los mercados europeos.

A principios del siglo XX, la ruta de la línea férrea incluía lotes pertenecientes a los clanes Rohrmoser, Castro, Von Schröeter, Sánchez, Dent, Tournón, Montealegre, Keith, Lindo y Jiménez, solo por citar algunos de los más connotados. Aparte de sus fincas, que variaban en tamaño (las más grandes se encontraron en Pavas, pertenecientes a los Rohrmoser o las de Jiménez y Lindo en Turrialba); estas familias también poseían los principales beneficios o plantas de procesamiento de café.

Es necesario retomar parcialmente los postulados del historiador geográfico Edward Whiting Fox (1998), quien señala que las ciudades-centros en el mundo agrícola se convertían en los asientos tanto del mercado principal, como en los puntos de convergencia de las élites. La expansión y dimensiones de estos centros dependían principalmente de los medios de transporte, su integración y control de las zonas periféricas agrícolas, así como del uso que le podían dar a los excedentes de la producción, es decir su colocación en mercados externos.

En otras palabras, las ciudades en una lógica rural eran meros centros comerciales y de gobierno, solo podían crecer a través de la integración de nuevos campos de plantación; y para ello dependían estrictamente de los tipos de transporte y tecnología que tuvieran a disposición. En los casos en que solo se contaba con transportes rústicos y no había ríos navegables, el área de influencia de las ciudades abarcaba desde la urbe como tal, hasta donde la carreta pudiera llegar a recoger productos en un tiempo prudencial. Precisamente, ante los terrenos o climas tortuosos que frenaban el desarrollo de caminos óptimos, las ciudades se mantenían estáticas y sumidas en el agro de auto-subsistencia.

En este punto, se pueden traer a colación las observaciones de la geógrafa Carolyn Hall (1989, p. 42), cuando apunta que el desarrollo tecnológico era vital y provocaba grandes modificaciones en el paisaje rural o agrícola. Y es que precisamente, cuando los medios de transporte mejoran, como por ejemplo, gracias al ferrocarril; las ciudades y su radio de acción pueden crecer. Esto se acentúa al 
abarcar nuevas áreas, creando mercados e incluso, en determinadas ocasiones se puede acelerar un proceso de especialización productiva e integración con otras ciudades, países y eventualmente, hasta continentes.

Precisamente, este marco puede aplicarse para estudiar sitios como Curridabat y otros afines. Según los datos recopilados, en tiempos coloniales y hasta por lo menos, mediados del siglo XIX, la localidad se caracterizaba por su relativo aislamiento y por el predominio de los bosques, algunos potreros y explotaciones agrícolas; pero sobre todo, era una zona de paso, que comunicaba la antigua metrópoli de Cartago con San José. El desarrollo del café, como la misma Hall (1989) expone, permitió que la ciudad-centro San José se expandiera y en especial difundiera su control efectivo sobre los territorios periféricos.

De esta forma, Curridabat, que poseía terrenos fértiles y una población semiestable desde tiempos coloniales; fue rápidamente integrada al cultivo del café como un abastecedor del mercado central, cuyo eje se encontraba en la capital. El viejo caserío debió ensancharse para suplir de alimentos a los carreteros locales y aquellos que venían de otras poblaciones con rumbo a San José y de ahí, al puerto del Pacífico, única ruta para la salida del café en aquellos años. A finales del siglo, con la llegada del ferrocarril, está lógica se consolidó, pues con toda seguridad se facilitó el comercio; ya que ahora las carretas recorrían distancias menores, pues solo debían alcanzar la línea férrea ubicada en medio del actual cantón de Curridabat y que se dirigía a la costa atlántica (Hall, 1976, p. 73).

\section{Curridabat y su inserción en el paisaje cafetalero}

Describir un paisaje fiel del Curridabat decimonónico resulta una tarea un poco azarosa, puesto que las fuentes consultadas no proporcionan mayores luces al respecto; aunque de manera general se caracterizó -entre la época colonial y los albores del siglo XIX- por la presencia de haciendas ganaderas, de trigo, milpas y trapiches: las cuales después 1830 dieron paso a los cafetales, mismos que coexistirían a partir de entonces con potreros y amplios remanentes de bosques. ${ }^{9} \mathrm{De}$ acuerdo con algunas fotografías disponibles y ubicables en el año 1922, las fincas de café eran comunes en el lugar, apegadas al modelo que se había impuesto en el resto de la Meseta: matas de la variedad arábiga, cogedores de café descalzos, las infaltables carretas y los caminos de tierra. ${ }^{10}$

La reconstrucción más precisa se podría comenzar a dilucidar para el año 1904, a través de los censos agrícolas. Si bien, este documento no ofrece datos específicos de Curridabat, ya que este era un distrito de San José, sí permite apreciar lo que podría definirse como un paisaje "generalizable", que sin duda primó en las zonas cafetaleras bajo la jurisdicción josefina. De esta forma, la ciudad capital contabilizaba unas 6.589 
manzanas de café, más de 10.000 manzanas de potreros (naturales y artificiales), y unos 50 beneficios de café (la mayoría de vapor); así como unos 38 trapiches, 110 lecherías y numerosas fábricas de tabaco (unas 68). Además, se presentaba gran cantidad de ganado, tanto vacuno, como porcino y caballar, primando el primero con más de 7.800 cabezas. A este cuadro también se sumaban diversas tenerías y serrerías. ${ }^{11}$

En el Anuario de Agricultura e Industria de 1907, la superficie dedicada al cultivo de café en San José superaba las diez mil hectáreas, los maizales también destacaban con más de 6.000 ha, mientras que otro dato indica que entre montaña y monte se presentaban más de 78.000 ha. Lo anterior permite aseverar que el bosque era el rasgo predominante del paisaje. Aparte de los cultivos ya mencionados, se explotaban cacao, tabaco, yuca, papas, frutales y frijoles, entre otros. En cuanto a beneficios de café, se registraron 67, diversos trapiches, cinco fábricas de puros, 225 lecherías; y en ganado sobresalían las vacas, los cerdos y los bueyes: casi nueve mil (República de Costa Rica, 1908, p. 196). El historiador Carlos Naranjo proporciona datos de mayor precisión para este año (1907) pues indica que en Curridabat -en fincas como La Laguna o Hernández- existieron diversos beneficios de Primera Clase (los más avanzados de la época), movidos por vapor o agua, que contaban con secadoras del grano y que pertenecían a los clanes González Soto, Gutiérrez, Jiménez Oreamuno y Von Schröeter. ${ }^{12}$

En términos generales, aunque el citado Anuario es diferente al censo de 1904, ya que se percibe mayor exactitud con respecto a las explotaciones agrícolas, lo importante en este caso es el predominio del espacio dedicado a la agricultura, ganadería y la presencia de importantes remanentes de bosque. Las descripciones propias de la época se refieren a un Curridabat de potreros, cafetales, platanares, árboles frutales y cañaverales, en las numerosas fincas de la localidad. También se mencionan algunos riachuelos rodeados de charrales, árboles de gran tamaño, como los higuerones, porós y otros. Lugares como Tirrases se caracterizaron por la primacía de bosques, los cuales eran destinados a la extracción de leña y pedregales; aunque luego fueron convertidos en milpas (Sánchez, 1995, p. 30).

Incluso se podían observar diversas especies de la fauna de la localidad, tales como ardillas, aves, venados, culebras (loras, tobobas y zopilotas), armadillos y monos congo. En las descripciones de José Sánchez (1995) se comenta que para el periodo 1910-1920 aproximadamente, los cambios habían sido en una escala notoria. Por una parte, los animales y las zonas boscosas disminuyeron, mientras que las actividades ganaderas y las lecherías se imponían poco a poco en las áreas colindantes con el actual San Diego de Tres Ríos.

Las referencias populares no solo mencionan el paisaje agrario, sino también las edificaciones: casas de adobe, pisos de tierra y calzadas de piedra. También primaban las viviendas amplias, propiedad de la élite cafetalera que vacacionaba 
en sus fincas rurales. Las más importantes contaron incluso con una extensa infraestructura cafetalera: el beneficio, varias bodegas, maquinaria para la actividad agrícola y amplias cañerías conectadas con los ríos más importantes.

Gracias al Censo Cafetalero de 1935-36, se cuenta con una de las imágenes más nutridas del paisaje agrario del joven cantón. Con estos datos se puede precisar que el número de fincas ascendía a 392, abarcando un área de 2.027,75 manzanas, de las cuales 1.664 eran de café, 338 de otros cultivos y 25,25 eran terrenos baldíos. Casi la mitad del área cafetalera se concentraba en el distrito central, lo que equivalía a 785 manzanas, mientras que Granadilla sumaba 272, Sánchez 392 y Tirrases 214 (Instituto de Defensa del Café, 1935, pp. 323-327). Asimismo, contaba con 5 beneficios, cantidad aparentemente irrelevante, pero sí se suman los 7 que poseía su pueblo vecino, Montes de Oca, los ubicados en Goicoechea (4) y los de Moravia (2), se obtenía un total de 18; dato que revela la importancia de estas zonas, no por su extensión total de manzanas de café, sino por la concentración de plantas procesadoras de grano en el este de la capital. Por ejemplo, el cantón de Desamparados, mucho más amplio (con más de 7.000 manzanas de café), presentaba solo 5 beneficios (Rojas, 2000, pp. 40 y 68).

La maquinaria, aparte de los beneficios ya citados, incluía 24 arados, 7 camiones, 2 tractores y 106 carretas. ${ }^{13}$ Aunque es notoria la presencia de estos aparatos, se debe recordar que muchos de los centros de procesamiento del grano eran propiedad de la élite cafetalera y que por ello no debe resultar del todo sorpresiva la presencia de este equipo. Precisamente, en cuanto a los propietarios de finca, las estadísticas aclaran que la mayoría abrumadora eran nacionales (297) y unos pocos extranjeros. ${ }^{14}$

En cuanto a los abonos, 112 fincas los empleaban y abarcaban casi el 75\% (1.235) de las manzanas cubiertas de café; esto da indicios de que los suelos podrían estar perdiendo fertilidad a una velocidad alarmante y ello constituyó un grave problema a mediano plazo.

Por último, también se puede realizar una revisión superficial en torno a la composición socio-laboral del cantón, pues de los empleados cafetaleros, 406 eran peones, 26 eran boyeros, 22 mandadores, 12 sirvientes y 5 choferes. Un dato final, que debe ser tomado en consideración, es que los beneficios registrados en Curridabat en este lapso correspondían a los señores Max Koberg y Manuel Francisco "Lico" Jiménez Ortiz, ambos destacados miembros de la élite, Jiménez en particular, fue ministro y miembro preeminente de la facción cafetalera. ${ }^{15}$

\section{El prototipo de centro urbano del joven cantón, entre 1910 y 1940}

Paralelo a la consolidación de un paisaje predominantemente cafetalero, comenzó a desarrollarse un pequeño cuadrante central que daría paso, décadas 
más tarde, a una ciudad satélite de San José. Popularmente al centro "urbano" de muchos cantones de Costa Rica se les conoce como "pueblos", puesto que considerarlos como urbes es impreciso. Por lo general, son unas pocas manzanas, con la iglesia, la plaza principal, los edificios administrativos y unas cuantas casas. Tradicionalmente los asentamientos se habían concentrado en la región suroeste del actual cantón, incluyendo el distrito central de Curridabat y posteriormente, el de Tirrases (véase el Mapa $N^{\circ} 1$ en los Anexos). Las cuadras primitivas fueron diseñadas por Braulio Carrillo, después de la destrucción ocasionada por el terremoto de San Antolín en 1841, lo que señala la existencia de una proto-villa, a partir del periodo 1840-1850 (Muñoz, 1990, p. 62).

En cuanto a servicios básicos, desde el año 1909 fueron frecuentes las construcciones de puentes y alcantarillas para manejar las acequias de la localidad, más específicamente en el norte, entre Granadilla y Guayabos; con la finalidad de abastecer de agua a estos pueblos y probablemente a las fincas cercanas. En 1913, la localidad presentaba un sistema de cañería que ofrecía agua potable, y se planeaba extenderla como parte de un proyecto para proveer a otras regiones como San Francisco de Dos Ríos. Años después, en 1935, se solicitó el aumento de los impuestos para las compañías eléctricas que servían calefacción, luz y fuerza motriz y que se encontraban en Curridabat; a la vez se acusó a estas empresas de no aportar lo suficiente para desarrollo local y en cambio, si explotaban demasiado a los pobladores (Archivo Nacional de Costa Rica, 1913, Fomento No 8044 y Municipal No 10128), (Archivo Nacional de Costa Rica, 1935, Congreso $N^{\circ}$ 17506). En suma, la región contaba con servicios básicos como agua potable, electricidad y algunas obras de infraestructura (puentes y caminos, principalmente), muy lejos de la visión de pobreza que algunos documentos y obras de historia local pretendían construir.

En la periferia se encontraban caseríos dispersos que, a simple vista, lucirían como marginales, algunos como La Laguna presentaron suficientes habitantes como para demandar una escuela; además, los pobladores afirmaban encontrarse muy lejos del centro y por ello era indispensable que se les ofreciera tal servicio. En este lugar, colindante con una finca de Minor C. Keith, se incluían los pequeños barrios de La Cerveza, La García, Romero y La Itaba, los cuales limitaban al norte con el actual Concepción de Tres Ríos, al sur con el río Tiribí, al oeste el Distrito Central y al este con San Diego; lo que demuestra que el distrito central no era el único relevante en este periodo y que por ello mereció una infraestructura moderna; más cuando se toma en cuenta que La Laguna era una de las haciendas cafetaleras más importantes durante esta etapa (Archivo Nacional de Costa Rica, s.f., Educación $\mathrm{N}^{\circ}$ 10769). De lo anterior, también se deduce que los primitivos caminos y medios de transporte imposibilitaban el acceso a servicios básicos, incluso en lugares tan 
pequeños como Curridabat, donde las distancias entre barriadas eran de unos pocos centenares de metros. Esto explica el gran cambio que implicaba la mejoría en los transportes, al acortar distancias y acercar comunidades.

Por otra parte y para enfatizar en el curioso sentido de lejanía que se tenía de Curridabat con respecto a San José; el edificio que mejor ejemplifica esta idea fue el Asilo de Leprosos Las Mercedes (llamado luego "Sanatorio"). Este se ubicó en Tirrases dentro de la finca del mismo nombre, en una región que las fotografías muestran como predominantemente boscosa y por ende aislada, pues en esa época se abogaba por medidas de cuarentena, para evitar la diseminación de la enfermedad (Archivo Nacional de Costa Rica, Fotografías No 211) (Leiva, 2008, p. 59). Durante el siglo XIX el lazareto se encontraba dentro de la ciudad capital, primero en La Uruca y luego en las cercanías de La Sabana (desde 1877 y hasta 1908).

Desde 1896 se intentó infructuosamente instalarlo en las islas del golfo de Nicoya, pero fue en 1903 que se ordenó su traslado definitivo a la finca ya citada, aunque el nuevo centro sanitario comenzó operaciones hasta 1909 y fue cerrado en 1979. ${ }^{16}$ Según los datos consignados, su infraestructura se encontraba en un mal estado relativo, por lo que demandaba al Ministerio o Secretaría de Beneficencia nuevos postes para el alumbrado, entre otras de sus insuficiencias. Tal era el grado de aislamiento que se pretendía conferirle al hospital, que en la década de 1940 se perforaron monedas para que fueran del uso exclusivo de éste y del Sanatorio Durán, que atendía la tuberculosis (Archivo Nacional de Costa Rica, 1913, Fomento No 5761) (Solano, s.f. p. 3).

Dado que Curridabat era concebida como una zona con amplias tierras explotables, en 1914 se remodeló la Escuela de Agricultura, en la misma finca Las Mercedes (probablemente otro predio de la misma que daba cobijo al Sanatorio). La versión original del centro educativo antecedía al asilo y se había intentado levantar entre 1892 y 1895, en la otrora hacienda del doctor Antonio Cruz (Herrero, 2009 , p. 381). ${ }^{17}$ La nueva obra consistía en un internado, donde se impartía cultura universal por medio de clases de moral, aritmética, historia y geografía; además de cuidados agrícolas (poda, abonos, uso de maquinaria y otros). Parte de sus objetivos era recibir estudiantes que provenían de cualquier lugar del país, además contaba con becas y otros tipos de respaldos por parte del Estado: 14 becas, dos por cada provincia. A pesar de sus nobles fines, el centro de enseñanza cerró sus puertas en 1919, debido a la crisis económica desencadenada por la Primera Guerra Mundial y la dictadura de los Tinoco. ${ }^{18}$

En cuanto a los aspectos más próximos a las actividades industriales, predominaban en San José las pequeñas fábricas de ataúdes, candelas, zapatos, herrerías, cervecerías y telares, entre muchas otras. Mientras que en Curridabat probablemente existieron algunos modestos talleres de zapateros y sastres y fue hasta 1934 
que se instaló la primera fábrica de escobas. Por su parte, el sector comercial tuvo mayor desenvolvimiento que el industrial. Para la década de 1910, se presentaron dos notorias pulperías: La Rosa y La Bola Blanca, cerca de lo que antiguamente se conoció como la Calle Real (frente a la actual sucursal del Banco Nacional), que comunicaba San José y Cartago, y que permitía el tránsito de las carretas. Estos locales eran expendedores de carne, pan, dulces, víveres, cerveza, aguardiente y tabaco. Lo que corresponde al rubro del trabajo femenino, las señoras se dedicaban, aparte de los oficios domésticos, a lavar ropa, preparar cigarros, tejer y pescar en el río Tiribí, cerca de Tirrases.

Para concluir este apartado, en 1930 se describía un Curridabat de pocos latifundistas, aunque algunos peones estaban emigrando a San Isidro de El General y otros sitios, siguiendo las corrientes que expandieron la frontera agrícola fuera del Valle Central. Con esto parecía que el sistema cafetalero mostraba ineludibles signos de agotamiento. Otro dato que revela los conflictos administrativos latentes se presenta en 1934, cuando el distrito de Granadilla solicitó al gobierno separarse de Curridabat e integrarse al cantón de Montes de Oca, tras acusar a las autoridades municipales de irresponsables por no dotarlos de una cañería adecuada, y por tanto de agua potable (Archivo Nacional de Costa Rica, 1934, Congreso No 17109). El caso parece irrelevante, pero en el documento se citaba que la municipalidad era reciente y apenas se estaba ordenando, además, eran unos pocos individuos interesados en integrarse a Montes de Oca, puesto que la mayoría no estaba de acuerdo. Lo anterior, no es una referencia pintoresca, al contrario, se orienta hacia puntos esenciales en el desarrollo de la comunidad.

Y es que San Pedro se convirtió en cantón en 1915, mucho antes que Curridabat, Este último se mantenía como distrito josefino, lo que implicaba ciertos problemas administrativos y de competencia con un vecino que ya estaba consolidándose como entidad autónoma, más cuando el control político se tornaba indirecto por parte de la capital. La queja de los vecinos antes citada, implícitamente demuestra que había tensiones en torno a la identidad local y que, en la práctica, aún no se había afianzado una comunidad inventada que legitimara a los grupos dominantes de Curridabat y cuyo programa sociopolítico básico fuera interiorizado por los lugareños; tema que más adelante será retomado. Era evidente que se estaba fortaleciendo un modesto centro de población, en plena transición de lo rural a lo urbano y con cierto desarrollo de infraestructura moderna. El café jugó un papel primordial en este proceso de cambio, pero no fue el único que propició la urbanización. La concentración de propiedades, el declive que el café comenzó a experimentar y los nuevos campos de inversión de la élite cafetalera propiciaron el nacimiento de la ciudad actual. 


\section{De campos cafetaleros a urbe metropolitana}

Los mapas de 1950 invariablemente incluyeron a Curridabat dentro de la zona cafetalera, la cual abarcaba buena parte del Valle Central y colindado con la región de producción de leche del norte (hacia Coronado y las montañas de Cartago). El café, en un total global, presentaba más de 5.000 fincas (unas 63.293 manzanas) y la zona lechera incluía otras 4.000 fincas, pero significativamente más extensas, abarcando 148.293 manzanas (Peterson, 1952).

Para el censo agropecuario del mismo año, Curridabat registraba un total 115 fincas (más de mil quinientas manzanas), de estas 107 se dedicaban al cultivo de café con una producción de 8.398 fanegas, 12 trabajaban con caña de azúcar, 63 con ganado vacuno, 42 fincas lecheras y 12 dedicada a la cría de caballos (Ministerio de Economía y Hacienda, 1953, p. 116). En cuanto al desarrollo energético, la leña continuaba siendo el principal recurso, mientras que el uso de la electricidad era reducido a tan solo 9 propiedades, o sea, 106 haciendas estaban sin servicio. Por su parte, en el tema de los transportes, aún primaba la carreta, destinada al trabajo en la finca y para movilizar la producción; mientras que una sola hacienda presentaba tres tractores, y la cifra de camiones se había elevado a diez, distribuidos entre siete propiedades, con respecto a los datos recopilados en 1935.

A partir de estos datos, no es posible emitir conclusiones apresuradas. Tomar la información de una manera superficial, en otras palabras, confiar en que los métodos de recolección y el procesamiento hayan sido estrictos; se podría afirmar que la superficie cafetalera disminuyó y aun más importante, que hubo un descenso notorio en el número total de fincas (de 392 en 1935 a 115 en 1950).

De tal modo: ¿cómo explicar un descenso en el número de unidades productivas cercano al 70\%, en un lapso de quince años? Se podrían aportar varias respuestas, las cuales son complementarias entre sí. La primera, al retomar el contexto de estas dos décadas, se precisa que la reducción es producto del impacto concreto de la crisis económica de 1929 y los subsecuentes problemas generados por la Segunda Guerra Mundial, que produjeron el cierre del mercado europeo y la captación de menores cotizaciones por parte de los nuevos compradores estadounidenses. Aunque los precios por saco de café eran inferiores a los de años anteriores, el país -en términos globales- debió aumentar su nivel de producción para mantener rentable el negocio (Acuña y Molina, 1993).

Esta misma caída en los importes pudo provocar que muchos productores medianos y pequeños optaran por abandonar el cultivo y se dedicaran a otras actividades agrícolas e industriales; o integrarse al creciente aparato estatal a partir de 1950, fruto de las reformas acaecidas en los cuarentas. Ya para esta época se percibía un ligero cambio en la estructura ocupacional, pues los campesinos eran 
desplazados por los obreros, especialmente aquellos que comenzaron a residir en Curridabat pero que trabajaban en los alrededores o en el centro de San José (La Prensa Libre, 1989, p. 4).

La segunda explicación se remite a lo planteado por Rojas, Samper y Torres (1994, p. 107) para el caso de las fincas de Alfredo González Flores y Delia Morales. De acuerdo con esto, Curridabat al encontrarse en una zona tradicional del café -similar a los cantones donde se localizaban las fincas de González Flores-, o lo que es lo mismo, en áreas que por casi un siglo estuvieron sometidas a un sistema productivo ajeno al uso intensivo de abonos; es muy probable que para 1950 presentara suelos agotados y esto incidiera en un abandono de las propiedades. Por lo general, en estos terrenos se aplicaban escasos fertilizantes orgánicos y fue hasta el decenio de los cincuentas que se comenzaron a utilizar agroquímicos y plaguicidas. Los citados autores precisaron que las empresas de González no sobrevivieron a los embates de los nuevos tiempos, sí bien las cotizaciones habían mejorado en la posguerra, era necesario introducir cambios afines a lo que luego se denominó como Revolución Verde; caracterizada por el empleo de variedades híbridas de porte bajo y el uso de un paquete tecnológico con predominancia de los agroquímicos. Es probable que muchos propietarios de Curridabat no pudieran costear estas modernizaciones y con ello fueron absorbidos por los grandes productores y algunos abandonaron del todo sus cafetales. ${ }^{19}$

Los datos consignados por los censos y lo anteriormente expuesto nos conducen a otra respuesta: la crisis de los años treinta no solo precipitó una serie de problemas dentro de la estructura productiva cafetalera -como la disminución del número de fincas-, también exacerbó los ánimos entre los distintos estratos sociales que la componían. Precisamente, a partir de 1932 surgieron una serie de organismos estatales que trataron de morigerar los conflictos entre los beneficiadores y los pequeños y medianos productores; iniciativas que desembocaron en la fundación de la Instituto de Defensa del Café, hoy Instituto del Café de Costa Rica (ICAFE). Estos episodios de tensiones daban señal de la expansión del capitalismo agrario dentro de la lógica cafetalera, lo que motivó a los beneficiadores y grandes exportadores a transferir sus pérdidas a los sectores más débiles de la cadena productiva.

Retomando los datos estadísticos ya expuestos, lo que realmente disminuyó fue la cantidad de fincas, no así el área de cafetales, que se mantenía cercana a las 1.500 manzanas (mientras que en 1935 se anotaban más de 1.600). Un aspecto más significativo, dado el gran número de camiones -que incluso había aumentado un poco entre 1935 y 1950-, fue la llegada de la electricidad y la gran importancia que tenían los beneficios en esta región oriental josefina. Lo que ocurría no era un declive del café, sino una paulatina concentración de las propiedades y un desplazamiento de la población campesina. Se podría intuir que estas clases subalternas 
experimentaron de primera mano los atisbos de un proceso de proletarización, enlazado con la industrialización ligera que tuvo lugar en Costa Rica a partir de 1960, en buena medida, debido a su incorporación al Mercado Común Centroamericano.

Este mismo proceso explica el desarrollo del cantón de Curridabat en la segunda mitad del siglo XX y que hasta el presente mantiene ciertos resabios. En esta nueva fase, los beneficios fueron paulatinamente reemplazados por grandes fábricas procesadoras de café, lo que dio asiento a empresas tales como Café Rey (1953, distrito central), Dorado (1954, también en el distrito central, luego se desplazó a Calle Blancos), Maravilloso (Barrio José María Zeledón), Volio (1976, Barrio San José) y Sánchez (en la localidad del mismo nombre). A pesar de los evidentes cambios en el paisaje, la base económica seguía siendo el café, pero en su rama agroindustrial.

Igualmente, a partir de 1970, la aparente concentración de tierras favoreció un proceso de cambio en el uso del suelo, que se intensificó entre 1990-2000 (tras las crisis del café en los ochentas). Esto provocó el abandono de las actividades agrícolas, puesto que las antiguas fincas fueron convertidas en lotes urbanizables y a partir de ahí, el paisaje fue orientándose hacia el uso actual de viviendas y comercios. ${ }^{20}$

Otro aspecto que favoreció el proceso de urbanización fue la construcción de carreteras con mayor número de carriles y por ende, con mayor capacidad vehicular (las llamadas "autopistas”, dentro del entorno costarricense). Así, en 1962 comenzó a funcionar la vía Curridabat-Zapote y más tarde, la autopista Florencio del Castillo, entre el cantón y Cartago. En muchos casos las zonas ocupadas por el asfalto fueron fincas cafetaleras, cuyos dueños las transfirieron al Estado por cuantiosas sumas. Esta infraestructura vial se convirtió, sin lugar a dudas, en un importante atractivo para los nuevos pobladores que arribaron en los setentas, fruto del poblamiento centrípeto que experimentaba el Área Metropolitana.

Empero, no fue únicamente este movimiento migratorio, producto de la industrialización y la especialización en servicios que experimentaba el casco josefino, o del agotamiento de la frontera agrícola; el causante del cambio en el uso del suelo. ${ }^{21}$ Es evidente que el acceso a servicios básicos (escuelas, clínicas, acueductos, etc.), que acumulaban cantones como Curridabat desde 1930, jugó un papel primordial y la concentración de valiosas tierras por parte de familias acomodadas. Otros atractivos adicionales en la conformación de este paisaje idealizado, y que no deben menospreciarse, fueron la vista panorámica al llamativo cerro La Carpintera y el supuesto buen clima de la zona.

Es destacable que el surgimiento de nuevas barriadas o residenciales se dio, en gran medida, gracias, a las élites cafetaleras, que decidieron reinvertir sus capitales en el naciente negocio inmobiliario. Esta transformación quedó ejemplificada con el caso pionero de la familia Terán, la cual en 1967 y ante una de las crisis 
del café, optó por fundar la Urbanizadora La Laguna. En las tierras de la hacienda del mismo nombre (establecida en 1856, ubicada en el distrito de Sánchez), se conformó el proyecto de vivienda hoy conocido como Lomas de Ayarco y que luego sería imitado en otros cantones como La Unión, Escazú y Santa Ana, entre otros (Camacho, 2004, p. 10).

Este auge inmobiliario de ninguna manera provocó un cambio inmediato en el panorama local. En los primeros años de la década de 1990, los cafetales, pastizales y charrales todavía eran predominantes en la región norte del cantón (distritos de Sánchez y Granadilla), incluso permanecían algunos beneficios; mientras el suroeste era de uso residencial-fabril (Tirrases y Curridabat) y en el sur se preservaron bosques, más específicamente en La Colina, parque ecológico ubicado en Tirrases (Instituto Geográfico Nacional, 1991). De acuerdo con el ICAFE, para el año 2001, se mantenían en el cantón unas 243 Ha de café, mientras que en el 2012 solo se registraban 165,2 Ha; concentradas en la parte norte. De estas, la gran mayoría se encontraba en el distrito de Sánchez (89 Ha) y en Granadilla (36,6 Ha); aunque parecían reservarse para el auge inmobiliario (grandes residenciales) que estaba teniendo su epicentro en dichos lugares (Instituto del Café de Costa Rica, s.f.).

Era claro que se había producido una fuerte especulación en torno a la venta de terrenos otrora cafetaleros (situación que también se dio en Montes de Oca), pues muchas fincas fueron urbanizadas en años recientes, esperando que su plusvalía alcanzara márgenes de ganancia óptimos. Al respecto, también se ha argumentado que en la segunda mitad del siglo XX, las clases acaudaladas que poblaban San José, especialmente el Barrio Amón, abandonaron la ciudad ante el vertiginoso crecimiento que experimentó entre 1950-1960 y se fueron trasladando hacia el este, primero en Los Yoses de Montes de Oca y luego hacia Curridabat, Pinares y La Unión de Tres Ríos; así como al suroeste, principalmente en Santa Ana y Escazú. ${ }^{22}$

Para el caso en estudio, también jugó un papel fundamental la construcción de edificios llamativos por su diseño, como el Colegio Federado de Ingenieros y Arquitectos (obra finalizada en 1981), nuevos condominios de múltiples pisos, clubes adinerados como el San José Indoor Club (inaugurado en 1976) y toda una plétora de instituciones educativas privadas; que terminaron por darle al lugar una tergiversada imagen de lujo y sofisticación. A su vez, esto incidió en que comenzaran a pulular centros comerciales, grandes supermercados y mega tiendas de ferretería, entre otros notorios edificios del nuevo sistema socioeconómico afín al libre mercado.

Sin embargo, todo este proceso de urbanización no dependió exclusivamente del café, otro proceso de suma importancia y larga data fue la reconstrucción del templo católico y su colaboración en la consolidación de un prototipo de identidad local, tema que será abordado en breve. 


\section{LA EDIFICACIÓN DE UN TEMPLO CATÓLICO DENTRO DEL PAISAJE CAFETALERO}

\section{Exaltando los pasajes olvidados de la memoria comunal}

Más que la búsqueda de leyendas, de anécdotas o la exaltación de personajes ilustres; la historia de los pueblos también puede enfatizar en las pequeñas, pero siempre perennes obras materiales (e inmateriales), fruto del esfuerzo comunitario. Lo idóneo no es perseguir identidades supuestamente olvidadas y que se presume vienen a llenar vacíos de nuestros días. Lo indicado es reconstruir fragmentos trascendentales de la memoria histórica colectiva y que parecen hallarse en el olvido.

De esta forma, lo que las siguientes líneas pretenden es profundizar en el curioso y vivaz proceso histórico que llevó a una pequeña comunidad cafetalera a embarcarse en la notoria construcción de un templo de grandes dimensiones. Un proceso de edificación que se extendió por décadas y que, guardando las distancias y proporciones, pareciera un eco modesto de aquellas grandes catedrales construidas en el Medioevo, las cuales demandaban siglos para su finalización y el esfuerzo, casi sobre humano, de generaciones enteras de pobladores que aportaban todo lo que tenían (dinero, productos agrícolas, su propia fuerza de trabajo, etc.), con tal de ver realizado el sueño ancestral de poseer un santuario, no solo de adoración religiosa, sino de preservación identitaria.

De esta forma, la comunidad de Curridabat, a partir de la década de 1910, decidió embarcarse en la osada labor de levantar un edificio religioso moderno, acorde con la época y similar a los que se inauguraban en otros cantones de Costa Rica, como el de Santo Domingo, Coronado o La Merced en San José, entre otros. Este proyecto no resultaría sencillo, especialmente por las limitaciones presupuestarias y por otra serie de vicisitudes que más adelante se explicarán.

Continuando con la sección anterior, la reconstrucción de este inmueble significó, más allá de la presencia religiosa, el punto de partida indispensable para consolidar una identidad local y, a partir de ella, construir un centro de control para la estabilidad y el eficiente desempeño del mundo cafetalero, que se mantuvo como agente dominante del paisaje hasta la década de 1990.

\section{Los templos católicos de Curridabat: de doctrina a parroquia}

A partir de la conquista y del ordenamiento territorial subsecuente, comisionado por las autoridades españolas, Curridabat permaneció por varios siglos vinculada a su vecina, Aserrí. Al ser ambas regiones indígenas, se demandó su 
pronta conversión al cristianismo, por ende, su evangelización estuvo a cargo de misioneros franciscanos que establecieron, entre 1570 y 1575, la doctrina conjunta de Curridabat y Aserrí. Asimismo, estos curatos obedecían, junto con el de Ujarrás y otros, a la Provincia de San Jorge, autoridad eclesiástica que agrupaba a las provincias de Nicaragua y Costa Rica, aunque los poderes máximos radicaban en la primera.

Entre los santos propios de los franciscanos -es preciso recordar que cada orden tiene sus santos y cultos predilectos- estaban San Luis encomendado para Aserrí y San Antonio de Padua, que fue asignado como patrón de Curridabat. La prioridad de los españoles era someter a los nativos y controlarlos rápidamente, función que la iglesia se aprestó a realizar de buena manera, pues prefirió emplear una estrategia ideológica por encima de las medidas violentas que caracterizaron la primera fase de la conquista. Asimismo, el sistema de encomiendas agrupaba a los indígenas en "pueblos de indios" (sobra aclarar que no eran ciudades), donde fueron evangelizados y destinados a trabajos forzados. La primera edificación tipo iglesia que se construyó en Curridabat correspondió a un mero "rancho pajizo". Es un misterio en qué año y lugar fue construido exactamente.

A inicios del siglo XVII, el lugar se caracterizó por el declive demográfico, puesto que la población total se aproximaba a los 200 individuos y para finales del mismo periodo se había reducido a poco más de un centenar. Según las quejas de las autoridades eclesiásticas, la doctrina del lugar no avanzaba en buenos términos, ya que los "indios" no asistían a las misas ni a las otras festividades religiosas. Es posible que la represión que se practicaba jugó un papel predominante en esta actitud contestaria, el mismo Thiel registró que los curas doctrineros se manifestaban en contra de los trabajos excesivos que los encomenderos imponían a sus tributarios, a tal grado que "a veces no veían a los indios ni en los domingos y los dias de fiesta" (Thiel, 1983).

Era evidente que la población indígena se encontraba en franca decadencia (las epidemias también jugaron un papel central) y esto motivaba su desánimo para participar en la vida religiosa, tal y como pretendían los curas doctrineros. A pesar de la escasez de población y la rebeldía que expresaban sus habitantes autóctonos, entre los años de 1681 y 1693, el Rey de España Carlos II recompensó a la provincia de Costa Rica por sus esfuerzos en combatir a los piratas y por ello, mandó que se edificaran mejores templos en los principales pueblos, por ende se reconstruyeron los santuarios de Aserrí, Curridabat y Ujarrás. Los dos primeros serían de adobe con horcones y el tercero de calicanto.

Para el siglo XVIII, la población del lugar creció levemente, acercándose a los 150 pobladores. En la visita realizada por el obispo Morel en 1751, Curridabat se ubicaba en un llano montuoso, con la iglesia y sus dependencias que 
incluían claustros y sacristía; pero el clérigo la consideró como una locación pobre y en condición decadente. La visión de Morel estaba un tanto fuera de contexto, pues no se podía esperar que una población reducida y dedicada a la agricultura de subsistencia pudiera construir un templo religioso de grandes dimensiones y lujos; con toda seguridad, la iglesia debió ser pequeña y no necesariamente "miserable", simplemente modesta. Al finalizar este periodo, más precisamente en 1776, Curridabat era consagrada, aparentemente, como parroquia; las razones no parecen claras y tampoco las nuevas funciones o potestades que podía desempeñar (Eco Católico, 1962, p. 446).

El siglo XIX fue una época de importantes cambios, por supuesto la Independencia marcó la transición hacia una nueva Costa Rica; aparte de que inició el complejo proceso de construcción de un Estado-Nación moderno. Ya antes de la autonomía política, se venía demandando la eclesiástica, específicamente, la separación de la autoridad religiosa con respecto a Nicaragua. Desde 1753, se comenzaron a emitir reales cédulas que recomendaban a las órdenes y doctrinas ceder sus labores a los cleros seculares locales (los clérigos costarricenses). A partir de 1802, las demandas aumentaron y para 1818, la Provincia Eclesiástica de San Jorge liberó de su cargo a los curatos de Curridabat, Aserrí y Ujarrás; a raíz de esto, los tres fueron erigidos como parroquias. No obstante, tras la separación de España, se intensificaron las diferencias entre el Estado y la Iglesia, que incluyeron la paulatina clausura de monasterios y la expulsión de los franciscanos y cualquier otra orden religiosa, lo que se cristalizó por medio de un mandato del gobierno guatemalteco en 1829 (Picado y Quirós, 2006, pp. 156-165).

Mientras estas disputas continuaban, los eventos más anecdóticos en que se vio envuelta la comunidad y la iglesia de Curridabat fueron los sucesos de la Guerra de la Liga en 1835; lucha en la que Cartago perdió la capital y se afianzó el poder de la élite josefina. ${ }^{23}$ De acuerdo con la tradición, los cartagineses portaban la imagen de la Virgen de los Ángeles (la "peregrina", no la original), pero al ser derrotados, abandonaron la efigie y fue precisamente la iglesia de Curridabat el lugar que rescató la imagen. Acto seguido, fue tomada por Braulio Carrillo, quien la empleó como un signo de que gozaba del favor divino y luego dispuso trasladarla a la capital con la finalidad de provocar mayores angustias entre los cartaginense. Años después fue devuelta a esta provincia.

Más que un detalle accesorio, la estadía de la afamada patrona nacional en el humilde templo de Curridabat debió significar un punto de partida para la consolidación de la identidad local, puesto que se manifestó devoción, tanto política como religiosa. Por lo tanto, constituye un episodio que se ganó un espacio en la memoria colectiva, hasta el día de hoy. 


\section{La atribulada génesis del actual templo católico}

El archivo parroquial, de acuerdo con muchas fuentes, se quemó en la primera mitad del siglo XIX; sin embargo, se conservan algunos documentos posteriores que se enfocaban en los esfuerzos de la pequeña comunidad por reconstruir su templo. Por ejemplo, para el año 1838 se comenzó formalmente el proceso para construir un mejor inmueble, sin embargo, las condiciones materiales parecían interponerse en la realización de dicho proyecto:

\footnotetext{
Habiendo hecho presente el Alcalde de cuartel y otros vecinos del barrio de Curridabat estas aquella Iglesia con necesidad de reedificarla y siendo esto una obligación a que eso deben negarse a contribuir todos los vecinos por no haber fondos disponibles, piden se les dé una orden para poder acumularlos, respecto a que algunos se niegan a hacer este servicio, y que se acordó comisionar al Señor Padre Cura de aquella ermita Presbítero Nicolás Bonilla para que sirva por medio de su exhortación manifestarlo al Pueblo por el pulpito a fin de que contribuyan (Archivo Nacional de Costa Rica, 1838, Municipal № 473).
}

A partir de este momento, se destacó que la obra debía ser impuesta a los vecinos y que estos mismos debían encontrar las formas de ahorrar o asegurarse los fondos necesarios; por consiguiente, la construcción del templo no parecía una obra fácil. En los años venideros, las peticiones por fondos y colectas se hicieron constantes y las autoridades locales solicitaron el apoyo de las estatales para concretar la evasiva obra, afirmaban: "Vista la solicitud de la Municipalidad de Curridabat suplicando se le dé permiso para colectar una limosna en toda la República con el fin de llevar adelante y concluir la Iglesia Parroquial de aquel pueblo" (Archivo Nacional de Costa Rica, 1848, Gobernación No 26699, folio 17).

La construcción del nuevo templo obedeció a órdenes expresas de Braulio Carrillo y la destrucción provocada por el terremoto de 1841. De este modo, el mismo Carillo supervisó el trazado de caminos y de algunos edificios, que después dieron forma al actual Curridabat. ${ }^{24}$ Aparentemente, para mediados del siglo XIX, la iglesia se pudo concluir, a pesar de que su forma y características no son muy conocidas; pero lo que sí se registró fue que la parroquia carecía de fondos y mantenía una serie de tribulaciones. En 1846 se solicitó al gobierno que permitiera: “...enajenar el terreno nombrado los Tirrases, para proveerse de recursos con que construir formalmente la Iglesia" (Archivo Nacional de Costa Rica, 1846, Gobernación $\mathrm{N}^{\mathrm{o}} 24839$, folio 8), lo que permite deducir que para la comunidad, aún no existía un verdadero templo. Tres años después, la situación más bien empeoró, ya que algunos vecinos no cumplieron con su trabajo y abandonaron las obras, incluso 
algunos incurrieron en robar los recursos de la iglesia.$^{25}$ Otro dato consignado indica que, en 1886, el cementerio, como era costumbre ancestral, estaba ubicado dentro de los terrenos de la misma iglesia y que era frecuentado por animales del lugar que provocaban constantes daños y problemas de salubridad (Archivo Nacional de Costa Rica, 1886, Judicial No 3846, folio 2).

A partir de la década de 1880, Monseñor Bernardo Augusto Thiel llevó a cabo una serie de visitas pastorales por todo el territorio costarricense, con la finalidad de supervisar el mejoramiento de la institución católica y que ésta pudiera hacer frente al poderío ideológico que mostraban los liberales. Son muchas las notas que reportó en torno a Curridabat, aquí señalaremos solo algunas: en 1889 destacó que, dado lo reducida que era la villa, se carecía de una casa cural, por lo que el sacerdote debía alquilar una particular en las vecindades; resultando esto una verdadera ignominia.

Cuando en 1895 volvió a visitar el lugar, solicitó que se limpiaran los cálices y los instrumentos del bautisterio, que se comprara un reloj para la torre y se mejorara el altozano de la iglesia, aunque fuera con unas matas de café. Lo más llamativo de sus demandas es que rogaba al clérigo local, Rafael Ramírez, abstenerse de la ingesta de cualquier bebida alcohólica. Tres años más tarde, el prelado repetía muchas de sus recomendaciones, sobresalía que ya se había constituido una junta para levantar una nueva iglesia y Thiel exhortaba para que se tomaran los mayores cuidados y evitar el derroche de recursos. También planteó, que si era útil, montaran una ladrillera propia (Herrero, 2009, pp. 500-501).

El siglo XX comenzó con nuevas solicitudes de parte del párroco local para obtener fondos para comprar campanas y otras necesidades de carácter eclesiástico, como se muestra en el siguiente fragmento:

\footnotetext{
...careciendo de fondos la tesorería de dicha junta para el pago de un víacrucis en relieve, fundición de una campana y otras atenciones de menor importancia; y no contando con otros medios para allegar recursos que el de celebrar algunos turnos, la junta en sesión última ha acordado solicitar de Vuestra Excelencia como tengo el honor de hacerlo, permiso para celebrar cuatro turnos en ésta localidad, con el intervalo de tres meses de uno a otro (Archivo Nacional de Costa Rica 1903, Policial No 1461).
}

El párroco Hilario Cajigas emprendió oficialmente el proceso de edificación en 1905. Para 1908, se habían encargado pilas para el agua bendita y rejas de hierro para la puerta. Un año después, se presentaron los diseños del nuevo templo, elaborados por el connotado ingeniero Lesmes Jiménez, quien también había trazado el plano del Colegio Superior de Señoritas, de estilo neoclásico. Este prototipo del santuario se caracterizaba por carecer de cúpula, mientras que el actual sí la 
presentaría. Asimismo, las capillas laterales eran más complejas, pero la fachada es desconocida (Archivo Histórico Arquidiocesano, 1916). El 29 de mayo de 1909, con gran júbilo se celebró la colocación de la primera piedra. A partir de ese momento se buscaron recursos para sufragar la obra, por ello, era común que el sacerdote de la localidad tuviera que organizar una serie de "turnos" y rifas para financiar la reparación del templo, ya que la población era reducida, mayoritariamente pobre y las labores, costosas (Archivo Nacional de Costa Rica, 1922, Judicial-Secretaría de Gobernación No 2167).

Sin embargo, estas iniciativas se vieron truncadas cuando el terremoto de 1910 destruyó los muros y las capillas; y partió la fachada de arriba a abajo; lo que frenó por más de una década el proceso de reconstrucción (Muñoz, 2007, pp. 4-5). Es interesante que en 1913 se mencionaba la realización de trabajos (reparaciones) en una iglesia vieja, mismos que se extendieron hasta 1915. Esta iglesia parece corresponder a la anterior, construida entre 1840 y 1850 y que se mantuvo dentro del armazón de la nueva, aunque en un estado verdaderamente deplorable.

Entre los años 1920-1922, el inmueble viejo fue demolido totalmente. A partir de estas ruinas se levantó el nuevo, pero con diseño y planos diferentes al que se trató de edificar en 1909 y se concluyó gracias a los encomiables esfuerzos del cura Anselmo Palacios. La empresa se realizó con el apoyo de la banca (el Banco Anglo Costarricense), las rifas de artículos tales como leña, relojes, muñecas y conejos; y las donaciones de los mismos feligreses (Archivo Histórico Arquidiocesano, 1930). Los planos fueron diseñados por el afamado arquitecto Teodorico Quirós, mismo que supervisó las labores ${ }^{26}$ Los materiales que se emplearon fueron cemento, ladrillos, madera de cáñamo, cedro y todos los otros que demandan una obra de esta envergadura. Los salarios de los múltiples obreros eran variados, dependiendo de su especialidad y rondaban desde menos de un colón hasta los sesenta; incluso se obsequiaban botellas de ron a las personas involucradas en la obra.

La fachada por fin se inauguró en 1926, aunque el edificio completo fue concluido y bendecido en 1933 por el entonces Monseñor Rafael Otón Castro (Curridabat, 1988). El santuario resultante correspondía al estilo arquitectónico neocolonial, conformado por tres naves, seis columnas y cuatro pilares que sostiene la cúpula. En la base de esta última se presentaban cuatro escudos, los cuales correspondían al de Costa Rica, España, el papal y el del prelado. También exhibía diversas pinturas con la vida y milagros de San Antonio de Padua, localizadas en las escalinatas y encima del altar.

\section{El santo patrono, las festividades y el estilo arquitectónico del templo}

Desde su fundación como doctrina el santo patrón de Curridabat es el monje franciscano San Antonio de Padua (1195-1231), nacido en Lisboa y cuya labor 
se concentró en la ciudad italiana de Padua. Es un santo muy popular y un gran atractivo para las masas de feligreses, por ejemplo, se considera que al colocar cabeza abajo su imagen se obtenía éxito en las relaciones amorosas o se encontraban objetos perdidos. También es patrono de las mujeres con problemas de fertilidad, de los panaderos y de los pobres. En vida defendió a los más necesitados y a los presos, las multitudes acudían a sus sermones y le rompían sus vestiduras para obtener milagros. En lo fundamental, se le considera un hombre muy noble, culto y generoso. Murió un 13 de junio y la fecha marca las celebraciones contemporáneas en su nombre (Siervas de los Corazones Traspasados de Jesús y María, s.f.).

En Curridabat, las fiestas en honor a San Antonio consistían tradicionalmente en una misa el 13 de junio. Dependiendo del entusiasmo y capacidad organizativa del párroco, se celebraban turnos y se preparaban variadas comidas típicas. En 1933, durante la inauguración oficial del templo, celebrada también el 13 de junio, Monseñor Rafael Otón Castro afirmó que los sacerdotes locales realizaron un gran desfile, muy ordenado, con arcos y guirnaldas, mientras se entonaban los cantos religiosos de rigor (Archivo Histórico Arquidiocesano, 1933, p. 369). Por ejemplo, otra celebración muy llamativa y fastuosa tuvo lugar en 1961, puesto que las fiestas patronales contaron con una filarmónica, desfile de campesinos, rifas y la duración fue más extensa de lo común (Eco Católico, 1961, pp. 3-4).

En cuanto a los aspectos arquitectónicos, un punto que influyó poderosamente se relaciona con los fuertes sismos que sacudieron al país y devastaron la infraestructura nacional. Estos movimientos tectónicos mostraron al Estado la necesidad de ajustes en los códigos de construcción, lo que se tradujo en edificaciones más resistentes y con materiales más duraderos como el cemento y el ladrillo; desplazando paulatinamente al adobe y el bahareque (Fonseca y otros, 1998, p. 320). De forma paralela, los cambios producidos en el seno de la Iglesia, originados en las disputas con los liberales desde finales del siglo XIX, provocaron que en las primeras décadas del siglo XX, las parroquias carecieran de apoyo y por ende, de mayor financiamiento por parte del Estado. En consecuencia, los nuevos templos se levantaron gracias al esfuerzo de las parroquias y sus comunidades.

En el caso específico del templo de Curridabat, presenta un estilo neocolonial, el cual consiste en una restauración nacionalista, que busca conectarse con las raíces hispánicas y criollas e incluso con lo indígena. En sus primeros años la estructura religiosa tenía muros blancos, un amplio volumen, molduras barrocas y balcones internos. En términos generales, la obra arquitectónica muestra rasgos estilísticos muy sencillos, pero con un gran sentido de la estética, su fachada guarda un espacio en la parte superior de la puerta principal para una pequeña estatua de San Antonio, con campanarios en ambos lados y ángeles encima de estos. El interior del templo es modesto, con un altar pequeño y una cúpula en la que resalta una 
imitación de un cuadro de Rubens, elaborada por Gregorio Obando. Probablemente, es la única obra artística intacta que conserva el templo, ya que las otras, imágenes de los milagros de San Antonio ubicadas detrás del Altar Mayor, han sido alteradas en los últimos años y se han agregado nuevas.

Los vitrales del templo representaban sencillas cruces de colores amarillo y blanco, pero la mayoría han sido reemplazados por otros que personifican a santos e íconos cristianos (colocados después del año 2000). Los vía crucis ubicados en los muros también son recientes. En cuanto a las imágenes de santos y similares, no se encuentra ninguna referencia disponible, aunque muchas son nuevas, ya que se dañaron en los años noventa por sismos, antigüedad y otros problemas. Asimismo, se afirma que el templo tuvo fascinantes confesionarios góticos y lámparas de tipo barroco, pero todos estos elementos desaparecieron de forma inaudita (Curridabat, 1988, pp. 4 y 9).

\section{Creando identidades, fraguando una ciudad entre los cafetales de Curridabat}

Las identidades se pueden definir como una serie de ideas, representaciones y acciones que se forman entre individuos, grupos y contextos específicos. Lo anterior, implica una serie de etapas en las que se trata de generar diferencias y similitudes con respecto a otros colectivos humanos; generalmente en áreas circunvecinas. El factor espacial posee un énfasis particular, pues en él se ancla el universo cultural y a partir de ello se construyen los simbolismos, los límites territoriales (los imaginarios y los reales), las relaciones materiales, los nexos entre ser humano y naturaleza; y por último, el control social. Cuando una sociedad logra consolidar su identificación con respecto a un espacio dado, consigue forjar un territorio; con ello obtiene un centro de control para todo su universo socioeconómico y de poder político (Méndez, 2012, pp. 42 y 449).

Imbricado en el proceso de consolidación de la identidad/territorio, se encuentra la urbanización. Las ciudades contemporáneas implican una superioridad tecnológica con respecto al campo, un sistema productivo afín al sector industrial y a los servicios, así como la concentración de población; lo que orienta en última instancia a la conformación de un núcleo político-administrativo. Esto quiere decir que una ciudad no es un simple conjunto de edificios y personas, es un eje neurálgico donde grupos humanos afianzan su identidad, su estructura productiva y las élites establecen su aparato de poder.

Aparte de lo expuesto, la identidad, sí bien trata de sostenerse a partir de elementos históricos y generar cohesión social; se torna peligrosa cuando degenera en mera identidad local o localismo, pues conlleva una profunda carga de mitificación, artificialidad y otredad (nosotros versus los otros). Similar al caso del 
nacionalismo, la identidad localista crea comunidades imaginadas dentro de ciertos límites geográficos y sus objetivos básicos, haciendo un eco de la misma Nación, son: "crear membrecía en comunidades reales/imaginadas, legitimar al régimen y su aparato institucional y socializar valores o normas convencionales" (Díaz, 2005).

En el caso concreto de la pequeña aldea que era Curridabat, se produjo una curiosa aproximación a la creación de una identidad localista. Dos vertientes tuvieron que entrelazarse a las alturas de la década de 1930: los esfuerzos del Estado por crear una subsidiaria del poder central josefino en el nuevo cantón y las iniciativas de la Iglesia Católica por afianzarse dentro de las almas de los pobladores; ambas -era evidente- no habían logrado sus cometidos y de forma intencionada o no, se originó una simbiosis o yuxtaposición de intereses.

Si recapitulamos lo expuesto en la segunda parte de este artículo, el café había tenido una notoria y exitosa expansión en las tierras del este de San José, hasta llegar a convertirse en su base productiva y gracias a este producto, el recién fundado cantón de Curridabat se había fortalecido dentro del modelo agroexportador que prevalecía en el país. Curridabat era una parte esencial del "hinterland" josefino, pero carecía de un centro urbano que le permitiera maximizar y eventualmente, modernizar el mismo sistema agrario que le daba sustento. Conforme la capital se expandía en infraestructura y población, el aparato público aumentaba en dimensiones y complejidad; era evidente que carecía de las herramientas y de la capacidad para dominar directamente a sus regiones periféricas. Por ende, se torno indispensable conceder a estos satélites independencia administrativa y que, por sí mismos, supervisaran su desarrollo.

Esto explica el porqué durante el siglo XIX, los intentos por separar a Curridabat de Aserrí, Desamparados o San José habían sido infructuosos; la respuesta era muy simple, la población fue mínima (una aldea dispersa), bastaba con una escuela como mecanismo indirecto para la reafirmación de la autoridad estatal y en definitiva, el país no precisaba de fútiles divisiones administrativas. ${ }^{27}$ De tal modo, gran parte de esta iniciativa para descentralizar la autoridad capitalina se realizó en 1914 e incluyó a Montes de Oca, Coronado, Moravia, Tibás y otros poblados afines; aunque Curridabat debió esperar quince años más.

Nuevamente, este retraso de más de una década demostraba que el programa tenía ciertos escollos por superar. La escasa población del entonces distrito era uno de los principales lastres, pues apenas sobrepasaba los 2.500 habitantes en 1927, aunque concentrados en un área relativamente pequeña. ${ }^{28} \mathrm{La}$ insistencia por constituir un cantón señalaba la posición estratégica que el sitio ocupaba, sin menospreciar la atractiva cantidad de beneficios que poseía y el hecho de que daba albergue a fincas pertenecientes a ilustres miembros de la burguesía cafetalera. También era evidente que estaba reuniendo a una pequeña élite local, que anhelaba elevar su estatus. 
Un problema adicional que debían superar estos noveles departamentos, era la falta de nexos internos. Para 1930 el proyecto de Estado-Nación emprendido por los liberales ya había alcanzado un nivel de madurez óptimo y los cuestionamientos que recibía estaban encausados en otras vías; el nacionalismo costarricense tal y como lo habían diseñado los intelectuales orgánicos entre 1880 y 1900 estaba bien resguardado. Esto no ocurría con las unidades políticas más pequeñas, como los cantones. Mientras los nacionalistas se habían enfocado en reforzar un territorio con fronteras definidas, una historia patria, efemérides, símbolos y el respectivo ideario que debía acompañarlas; todo parece indicar que fue la capital, San José, las cabeceras de las provincias y el grueso del grupo liberal, los que concentraron a la "intelligentsia" nacional y marginaron a las identidades localistas.

Por otro lado, la misma intelectualidad liberal que había concebido a la nación costarricense debía tomar las previsiones del caso y castrar con antelación cualquier proyecto de identidades paralelas que, eventualmente, -en un contexto determinado- podría generar una secesión o una abierta oposición a la democracia liberal. ${ }^{29}$ De ningún modo, estamos tratando de proponer que una localidad como Curridabat amenazó la estabilidad del proyecto nación, al contrario, fue una pieza orgánica del sistema cafetalero. No obstante, los problemas identitarios que le tocó sortear fueron fruto del relativo monopolio intelectual que ejercieron los liberales. Así, cuando finalmente se le otorgó el ansiado grado de cantón y poco después vio su templo católico finalizado, logró percibir que a su alrededor no se había generado una sólida identidad comunal.

No se podría definir categóricamente cuál es la identidad histórico-cultural dominante en el cantón, tanto en la década de 1930, como en los albores del siglo XXI. Sí es posible precisar que ha habido otros intentos por generar cohesión social a partir de visiones semi-míticas, uno de ellos es la indiscutible asociación del cantón con las antiguas sociedades autóctonas. Luis Ferrero, en el prólogo de la obra de José J. Sánchez, afirmaba que, en los primeros decenios del siglo pasado, el legado indígena era incuestionable entre los pobladores de Curridabat (Sánchez, 1995, p. 12). Además, el escudo cantonal y el nombre mismo del lugar "Curriravá" o sus múltiples variantes, hacen constante referencia a esta herencia indígena. Entonces, la pregunta es obligatoria: ¿qué ocurrió con este programa identitario afín al indigenismo?

Efectivamente, Ferrero estaba en lo correcto al señalar que la población de Curridabat era tanto indígena como mestiza, pero no se podía apelar a este pasado común como un mecanismo de unidad e identidad por varias razones. La primera es que la conquista en el siglo XVI, a pesar de los intentos por pretender lo contrario, fue un proceso traumático y violento para los pueblos autóctonos, seguido por siglos de sometimiento a la Corona Española. En segundo término, y esto era de repercusiones 
muy complejas, la represión indígena no era de origen exclusivamente colonial, sino también republicana, pues como se había señalado anteriormente, los pueblos de indios en lugares como Curridabat habían sido disueltos para favorecer el auge cafetalero de mediados del siglo XIX. Como tercer punto y final, el programa nacionalista de los liberales también despreció a la cultura autóctona, pues la consideraba como un enemigo de su capitalismo agrario, y ajena a las estereotipadas virtudes europeas que tanto se esmeraban en exaltar dentro del entorno costarricense.

Entonces, escudriñar demasiado en este pasado indígena y pretender una identificación con él resultaba peligroso e imposible, en la década de 1930, cuando se mantenía incuestionable el ideario nacionalista-liberal. Podría argüirse que estas nociones a favor de los indígenas fueron retomadas al finalizar el siglo y que se mantienen vigentes aún hoy, en el marco de una revalorización de los derechos y el legado de las sociedades autóctonas.

Ahora bien, esto tampoco debe generar conclusiones precipitadas y señalar que las identidades emergieron de su asociación con el poder eclesiástico. La Iglesia, para 1930, se encontraba en franca inferioridad con respecto al poder político y social del Estado; mantenía un férreo control sobre ciertos aspectos morales de la población, pero en términos generales, no se puede afirmar que estuviera en la capacidad de eclipsar al liberalismo de la época y su intrínseco patriotismo. Entonces, ¿qué resolvió el nuevo templo? El santuario proveyó de un "geosímbolo", de una referencia que paulatinamente transformó un paisaje meramente rural, en uno cultural, pues sirvió de pilar para un prototipo de identidad local, una que no necesariamente maduró, pero que dio la oportunidad de aglutinar edificios públicos en los cuadrantes colindantes con la iglesia: escuelas, plazas, mercados y lo más importante, viviendas.

A lo largo de este decenio (1930) y como se revisó en páginas anteriores, se construyeron obras públicas prioritarias, tales como cañerías, caminos y puentes; surgieron talleres, en fin, se construyó una pequeña ciudad. Todos estos componentes tendían a modernizar lo que antes era un paraje rústico. Para finales de los cuarentas, la electricidad comenzó a irrumpir y ya se estaba quebrando el monopolio del café sobre el paisaje.

Cabe recordar que para el levantamiento del templo se tomaron predios estratégicos: en un llano con vista a los cerros (La Colina, al sur), se resguardaron amplios espacios para los jardines, se mantuvo un atrio y contó con la plaza o parque para eventos masivos al frente de la puerta principal (posicionada al oeste como es común). Todo esto con el fin de generar la percepción de que el edificio era un centro, tanto de la urbe, como de lo sagrado. Habitar e integrarse cerca de este espacio simbólico representaba formar parte de la nueva congregación social que constituía Curridabat. 
La iglesia funcionó en virtud de ser la primera obra monumental que el pueblo levantó con sus propias manos y con escasa participación estatal. Era un símbolo de esfuerzo mancomunado, de muchos años de fracasos y desesperación. Incluso, a diferencia de los modestos templos que le precedieron, de escasa resistencia y duración, éste demostró sobrevivir a las inclemencias del tiempo y se convirtió en un legado para generaciones futuras, o por lo menos, esa es parte de la imagen que exhibe, puesto que sobrevivió al terremoto de 1991 y sigue en pie, a pesar de las tribulaciones pasajeras que ha enfrentado.

\section{Balance final}

Por lo general, se reafirmaría que el paisaje del cantón de Curridabat correspondió a uno meramente agrícola, rural o ambos; tales afirmaciones neutralizarían la riqueza del ambiente examinado. Es claro que en esta localidad se presentaron tres elementos de mayor preeminencia: los bosques, los potreros y los cafetales. La mayor parte de estos espacios se extinguieron a partir de la década de 1970, dando paso a un horizonte dominado por el cemento. Y precisamente de los resabios de ese arquetípico mundo cafetalero se ha fraguado la identidad y el actual paisaje percibido. El paisaje no se compone únicamente de los elementos materiales y naturales, es por mucho una construcción humana que expresa su ideología, sus anhelos, su visión de mundo, su poder y la forma en cómo un grupo social pretende que se visualice el espacio geográfico que habita.

Entonces, el actual Curridabat adquiere una mayor complejidad, que supera con creces las antiguas descripciones bucólicas de cafetales, árboles frutales y ríos cristalinos o las actuales, de centro urbano de vistosa arquitectura. Es un entorno que trata de expresar el éxito e integración que dio el café a unos pocos selectos moradores, la infraestructura atractiva que atrajo ingentes cantidades de población y su contemporánea percepción de ciudad-dormitorio, ya entrada a la capital nacional. Trata de proyectar éxito económico y modernidad, tanto arquitectónica como cultural. Pero a la vez, deliberadamente, pretende ocultar sus ambivalencias y las limitantes de su proyecto localista.

A diferencia de otros autores, que abrazan la tesis de que lugares como Curridabat, Escazú o Montes de Oca son el asiento de las clases pudientes josefinas; consideramos que esto es parte del intento por construir una identidad y un paisaje basados en percepciones distorsionadas y mitificaciones. ${ }^{30}$ Los grupos dominantes que habitan estos cantones anhelan presentarse a sí mismos como parte del triunfo de un ancestral sistema agroexportador, que evolucionó a un mundo dominado por los servicios y que está inserto en el libre mercado neoliberal. Tras este discurso, se esconde un pasado de privatizaciones de la tierra y de ruina campesina; y un presente de contaminación 
ambiental, amplios precarios, escasa diversidad laboral y la privatización, no solo en los rubros esenciales de salud y educación, sino de ocio y sociabilidad. ${ }^{31}$ Todas estas contradicciones son las que conforman el verdadero paisaje de la localidad.

Por otra parte, el significado del templo, más allá de lo religioso, fue proporcionar a la comunidad un edificio insigne que permitiera crear arraigo con el sitio habitado y convertirlo en un verdadero territorio, dominado y apreciado. Su mayor relevancia se da en el hecho de que su posición ha sido interiorizada como el núcleo mismo del cantón y a partir de éste, se organizaron los edificios, viviendas, carreteras y áreas verdes que conformaron posteriormente la urbe contemporánea. Este centro de veneración también se convirtió en un elemento fundamental del paisaje imaginado, pues es utilizado como un símbolo municipal oficial (parte del escudo cantonal) y es objeto de frecuentes representaciones artísticas por parte de la comunidad. Al margen de las idealizaciones, este templo católico es una muestra palpable del esfuerzo de una sociedad que, a pesar de los recursos limitados y la población reducida, salió adelante y consiguió heredar un legado cultural y arquitectónico de valor inconmensurable.

El presente estudio es, al final de cuentas, solo una visión preliminar en torno a una serie de temas claramente complejos y que demandan un análisis más profundo que el aquí desarrollado. Otras fuentes deben consultarse y nuevas interrogantes deberán ser planteadas. De momento, es un modesto intento por acercarse a la microhistoria y comprender en una escala más reducida, el impacto de procesos históricos tan fundamentales, como la expansión del café en la ecúmene de la Meseta Central costarricense y la emersión de identidades locales con fuertes tintes religiosos.

\section{CITAS Y NOTAS}

1 El autor quiere agradecer a todas las personas que colaboraron en la realización de este modesto artículo, a los estimables historiadores Carlos Naranjo Gutiérrez y José Daniel Gil Zuñiga, quienes leyeron versiones preliminares varios años atrás. Especial agradecimiento a Gertrud Peters Solórzano por darle un impulso final al mismo; así como a mi hermana Lorna, por elaborar el mapa.

2 Se optó por este periodo de cien años debido a la confluencia de fuentes provenientes de este lapso en específico, tanto del Archivo Nacional de Costa Rica, como del Archivo Arquidiocesano y algunos periódicos locales y nacionales. De acuerdo con la tradición, a mediados del siglo XIX se quemó el archivo de la comunidad, perdiéndose gran parte de su acervo documental, mito o no, la información disponible y de fácil acceso se encuentra en los años ya señalados. 
3 Consideramos que si bien la iglesia católica, para el periodo en estudio, aun concentraba un notorio poder político-ideológico, también debe tomarse en cuenta que distaba mucho de poseer la hegemonía en este campo. Por un lado, las reformas liberales de la década de 1880 y la expansión del aparato educativo público le había dado un golpe que alteró el predominio que tuviese en otros tiempos. Su denominado control social no era tan absoluto como la misma institución pretendía, ya que, por ejemplo, las quejas contras los sacerdotes (por abusos de diversa índole), planteadas tanto por vecinos como por otros clérigos, eran frecuentes y mostraban los límites de su aparato institucional. Para más detalles se puede consultar la obra de Elizabeth Poveda Porras: Moral tradicional y religiosidad popular en Costa Rica (1880-1920).

Una geografía histórica, concentrada en el estudio de paisajes del pasado, entendidos estos como una combinación de elementos naturales, tecnológicos, representaciones sociales, ideologías del poder, simbolismos, etc. Pero básicamente, no es el paisaje que se aprecia a simple vista, es todo el universo de relaciones y mensajes implícitos, de infinita riqueza que posee.

5 Otro aspecto muy llamativo de esta historia de escala reducida, es que revaloriza las acciones y personajes cotidianos, como los autores Pons y Sema indican, ¿quién decide que lo que sucedió en otra escala o a individuos sin relevancia especial es menos significativo? Efectivamente, tras décadas afirmando que la Historia no se concentra en los grandes personajes, ni en los supuestos "hechos" que cambiaron el rumbo de la humanidad; esto debería ponerse en práctica y concentrar los estudios en lo más próximo: nuestro propio entorno (Pons y Serna, 2004, pp. 6 y 15).

6 Leandro apunta que la iglesia y el pueblo de Curridabat cambiaron de ubicaciones varias veces y que en general, el primer asentamiento “español” era un misterio (1990, p. 4).

$7 \quad$ Uno de los principales templos de los que se tiene constancia, se construyó a finales del siglo XVII y hasta 1841, se ubicó en el actual emplazamiento del Convento de las Hermanas de María Auxiliadora, cerca del lugar conocido como La Galera (Muñoz, 2007, pp. 3-4 y 9).

8 La importancia del tendido ferroviario no puede menospreciarse; por ejemplo, un viaje en carretas desde San José a Puntarenas, tardaba de 4 a 6 días, mientras que el tren lo realizaba en 6 horas.

$9 \quad \mathrm{Al}$ menos, ese era parte del paisaje dominante en el conjunto Aserrí, Curridabat, Barva y Santa Ana, con 160 haciendas de trigo y ganado en 1662; 11 de ganado mayor y 159 propiedades con trapiches para 1747 (Molina, 2005, p. 542). 
10 Las fotografías revisadas corresponden a la Finca Castro en Curridabat y a la Hermes en Granadilla, ambas de 1922 y tomadas del álbum Costa Rica, América Central 1922 de Manuel Gómez Miralles (Centro de Investigaciones Histórica de América Central, s.f.)

11 Debe tenerse en cuenta que la exactitud de estos datos es bastante dudosa, pero que debe tomarse como una aproximación, como un fragmento de lo que fuera el paisaje josefino de inicios del siglo XX.

12 Precisar que existieron diversos tipos de beneficios, algunos mecanizados ya fuera con vapor o agua, otros sin ello; mientras que algunos carecían del todo de máquinas (Naranjo, 2007, pp. 66-71).

13 Del mismo modo, tenemos que el ganado al servicio del café estaba compuesto por 156 bueyes, 132 vacas, 116 terneros y 46 caballos (Peters y Rojas, 2010).

14 Cuatro extranjeros, correspondientes a un alemán, un español, un italiano y un guatemalteco; sus posesiones acumulaban 164 manzanas (Peters y Rojas, 2010).

15 Otras familias influyentes que poseyeron cafetales en el cantón a lo largo del siglo XX fueron las siguientes: Terán, Dent, González Lahmann, entre otras (Instituto de Defensa del Café, 1935, p. 337).

16 Contaba con solo 13 pacientes. En 1948 se convirtió en "Sanatorio", lo que implicaba que la estadía en el centro era solo temporal y no un confinamiento de por vida (República de Costa Rica, 1958, pp. 5-6).

17 Por su parte, Antonio Cruz fue un prestigioso abogado guatemalteco, trabajó en la elaboración de un nuevo código civil durante la administración de Próspero Fernández (1882-1885) y en su bufete comenzó a destacar un joven Ricardo Jiménez (Umaña, 2012, p. 14).

18 La escuela fue fundada por Luis Cruz Meza y dirigida por Gustavo L. Michaud (Archivo Nacional de Costa Rica, 1914, Congreso, Nº 10895) (Rojas, s.f.)

19 Con respecto al tema de la modernización de los cafetales, las crisis de precios de finales del siglo XIX y el paralelo agotamiento de los suelos que mostraban los cafetales vallecentralinos, obligaron a que se experimentara con nuevas técnicas de poda, expansión de la sombra para proteger las matas (de una forma más ordenada) y a la introducción de variedades del cafeto más resistentes a enfermedades (una de las más célebres fue la "Nacional Salvadoreño"). En síntesis, si bien la modernización se hizo patente después de 1950, el 
proceso para allanarle el camino había comenzado medio siglo antes (Naranjo, 1997, pp. 79-105).

Para el año 2000, Curridabat ya se clasificaba entre los productores marginales de café, con tan solo 6.000 fanegas, mientras que Tarrazú superaba las 200.000 o Pérez Zeledón con más de 500.000 (Alvarado, 2003, p. 26).

21 Hall había propuesto que para el decenio de 1970, la frontera agrícola -mal explotada- se había agotado y que se estaba produciendo una migración hacia el interior de la Meseta Central; dado que la ciudad de San José estaba ocupada por la industria y el sector servicios, estas masas de pobladores tuvieron que refugiarse en los principales cantones periféricos, como Tibás, Montes de Oca, Curridabat, Desamparados y otros. Aunque, esta explosión demográfica también fue producto de las mejoras en las condiciones de salud pública acaecidas después de 1950 que le estaban pasando factura a un país que no desarrollaba viviendas verticales y no planificaba correctamente sus nacientes ciudades (Hall, 1983, p. 303).

22 Curridabat, en palabras de Miguel Salguero, poseía un toque de distinción por la presencia de estos edificios y clases acomodadas (Salguero, 2007, p. 329).

23 Sandí anota que para 1848 Curridabat y Aserrí, aunque vinculados a San José, eran distritos parroquiales y cumplían funciones electorales; lo que es lo mismo, estas unidades podían elegir electores que a su vez emitirían votos para la presidencia de la república y también tendrían la capacidad de seleccionar diputados (Sandí, 2011, pp. 77-78). No obstante, debe tenerse claro que este poder político local podía terminar siendo solo nominal, puesto que el sistema democrático costarricense decimonónico era limitado, marginaba a la mayor parte de la población y los cargos relevantes eran concentrados por las élites y los potentados josefinos. Además, para 1844, Curridabat presentaba una población de tan solo 365 habitantes (más de 1200 en el decenio de 1860), descontando a mujeres, niños y todos aquellos varones que no podían votar por su situación socioeconómica; el número de votantes era ínfimo y es dudable que el sistema democrático significase algo verdaderamente trascendental en el otrora distrito. Precisamente, Clotilde Obregón explicitó lo anterior, pues de acuerdo con esta autora, para las elecciones de 1844 en Curridabat solo hubieron 42 electores, 40 en Aserrí, mientras que San José sumaba 769, Desamparados 201 y San Juan del Murciélago 157, solo por citar algunos. También agregaba que Curridabat, Aserrí y otros pueblos satélites, simplemente votaban por el candidato grato a San José (Obregón, 2000, pp. 17 y 113).

24 Lo extraño, es que Carrillo diseñó las obras en 1848, hacía mucho tiempo que había fallecido, probablemente se trató de un mero error en la consignación de los datos por parte de la autora original, con seguridad debía referirse a 1841 (Madrigal, 1974, p. 13). 
Fue el caso de Miguel Loría, quien abandonó las obras en 1849, además, corrían rumores de robos y situaciones similares (Archivo Nacional de Costa Rica, 1849, Municipal No 676, folio $17 \mathrm{v})$.

26 Mismo artista que diseñó las magníficas edificaciones de las parroquias de Santo Domingo y el templo neogótico de Coronado, verdaderas joyas de la arquitectura eclesiástica costarricense.

27 Algunos autores señalan con insistencia la presencia de múltiples escuelas en la comunidad (Rodríguez, 1998, pp. 29-30), estas con toda seguridad eran depositarias de la autoridad estatal, representantes -en especial después de 1870- de sus ideales de orden y progreso y su misión eran lograr el adoctrinamiento cívico de las masas o lo que es lo mismo, admirar y respetar a la democracia burguesa-liberal afín al capitalismo agrario.

Mientras que otros cantones como Montes de Oca, Santa Ana, Coronado o Tibás se encontraban en el margen de los 3.000-4.000 habitantes, Aserrí y Goicoechea superaban los 6.000.

29 Es claro que el nacionalismo se nutrió de los localismos del Valle Central durante el siglo XIX para lanzar su plataforma ideológica, sin embargo, debía impedirse que se desarrollara tal nivel de diferenciación, que entorpeciera la creación de una gran familia o comunidad costarricense, primero la patria, luego los pueblos (Palmer, 2004).

30 En cierto caso, se trata de reducir a cantones como Curridabat y Escazú a meros conglomerados de residenciales y centros comerciales, ambos a orillas de hermosas y verdes montañas. Una imagen romántica y poco fiel de la complejidad socioeconómica imperante en ambas localidades (Grané, 2011, 15A).

31 Percy Rodríguez hacía alarde de la cantidad de centros educativos que poseía la comunidad, menospreciando el hecho de que la arrolladora mayoría eran privados e inaccesibles para el grueso de la población. Recordemos que más de la mitad de la población nacional pertenece a los estratos bajos socioeconómicos, Curridabat no es necesariamente la excepción (Rodríguez, 1998, pp. 65-66). Por otro lado, las plazas y parques ofrecen al visitante mallas y candados, mientras que aumentan los pequeños y grandes centros comerciales, que implican capitalizar la convivencia humana y se han convertido en los templos modernos: fríos, impersonales e incentivando el consumismo. 


\section{REFERENCIAS}

Acuña, V. y Molina, I. (1993). Historia económica y social de Costa Rica (1750-1950). Costa Rica: Editorial Porvenir.

Alvarado, R. (2003). Cantones productores de café: formación y desafíos actuales. Costa Rica: Instituto de Fomento y Asesoría Municipal.

Archivo Histórico Arquidiocesano Bernardo Augusto Thiel. (1916). Fondos de la Iglesia de Curridabat (29 de marzo de 1905 al 31 de diciembre de 1916). Costa Rica: Archivo Histórico Arquidiocesano Bernardo Augusto Thiel.

Archivo Histórico Arquidiocesano Bernardo Augusto Thiel. (1930). Curridabat: Junta Edificadora . Cuentas de enero de 1925 a julio de 1930. Costa Rica: Archivo Histórico Arquidiocesano Bernardo Augusto Thiel.

Archivo Nacional de Costa Rica. (1838). Serie Municipal, $N^{o}$ 473. Costa Rica: Archivo Nacional de Costa Rica.

Archivo Nacional de Costa Rica. (1846). Serie Gobernación, $N^{\circ}$ 24839, folio 8. Costa Rica: Archivo Nacional de Costa Rica.

Archivo Nacional de Costa Rica. (1848). Serie Gobernación, $N^{o}$ 26699, folio 17. Costa Rica: Archivo Nacional de Costa Rica.

Archivo Nacional de Costa Rica. (1849). Serie Municipal, $N^{o}$ 676, folio 17v. Costa Rica: Archivo Nacional de Costa Rica.

Archivo Nacional de Costa Rica. (1886). Serie Judicial No 3846, folio 2. Costa Rica: Archivo Nacional de Costa Rica.

Archivo Nacional de Costa Rica. (1903). Serie Policial, $N^{\circ}$ 1461. Costa Rica: Archivo Nacional de Costa Rica.

Archivo Nacional de Costa Rica. (1913). Serie Fomento, $N^{o} 8044$. Costa Rica: Archivo Nacional de Costa Rica.

Archivo Nacional de Costa Rica. (1913). Serie Municipal, $N^{o}$ 10128. Costa Rica: Archivo Nacional de Costa Rica. 
Archivo Nacional de Costa Rica. (1914). Serie Congreso, $N^{o}$ 10895. Costa Rica: Archivo Nacional de Costa Rica.

Archivo Nacional de Costa Rica. (1922). Serie Judicial-Secretaría de Gobernación, $N^{\circ} 2167$. Costa Rica: Archivo Nacional de Costa Rica.

Archivo Nacional de Costa Rica. (1934). Serie Congreso, $N^{o}$ 17109. Costa Rica: Archivo Nacional de Costa Rica.

Archivo Nacional de Costa Rica. (1935). Serie Congreso, $N^{o}$ 17506. Costa Rica: Archivo Nacional de Costa Rica.

Archivo Nacional de Costa Rica. (s.f,) Serie Fotografías No 2113. Costa Rica: Archivo Nacional de Costa Rica.

Archivo Nacional de Costa Rica. (s.f.) Serie Educación, $N^{o}$ 10769. Costa Rica: Archivo Nacional de Costa Rica.

Archivo Nacional de Costa Rica. (s.f.) Serie Fomento, No 5761. Costa Rica: Archivo Nacional de Costa Rica.

Batista, M. (1993, 18 de julio) Barrios y ciudades, Curridabat. Al Día. p.17.

Camacho, A. (2004, 31 de julio) Una vida aderezada con casa y café. El Financiero. p. 10.

Castro, O. (1933). Libro de visitas canónicas. Libro IV. Costa Rica: Archivo Histórico Arquidiocesano Bernardo Augusto Thiel.

Centro de Investigaciones Históricas de Centroamérica. (s.f.) Colección Manuel Gómez Miralles. Disponible en: http://cihac.fcs.ucr.ac.cr/index.php?option=com_phocagallery\&view=catego ry\&id=7:coleccion-manuel-gomez-miralles\&Itemid=59.

Contreras, C. (2005). Pensar el paisaje. Explorando un concepto geográfico. Trayectorias., (17). pp. 57-69.

Curridabat. (1988) Curridabat. p. 9.

Dedicatoria a Juan XXIII. (1961, 15 de diciembre). Diario de Costa Rica. p. 4. 
Departamento Nacional de Estadística, Sección Agricultura. (1904). Primer Censo Agrícola General 1904. Costa Rica: Tipografía Nacional.

Díaz, D. (2005) Construcción de un Estado moderno. Política, Estado e Identidad nacional en Costa Rica. Costa Rica: Universidad de Costa Rica, Cátedra Historia de las Instituciones.

Eco Católico (1962, junio), p. 446.

Fonseca, E. et al. (1998). Historia de la Arquitectura en Costa Rica. Costa Rica: Fundación de Museos del Banco Central de Costa Rica.

Grané, J. (2011, 16 de mayo) Psicología urbana: Curridabat vs Escazú. La Nación. p.15A.

Hall, C. (1976) El café y el Desarrollo Histórico-Geográfico de Costa Rica. Costa Rica: Editorial Costa Rica.

Hall, C. (1983) Costa Rica. Una interpretación geográfica con perspectiva histórica. Costa Rica: Editorial Costa Rica.

Hall, C. (1989). La geografía histórica: un campo interdisciplinario entre la geografía y la historia. En: E. Fonseca. (Ed.). Historia. Teoría y métodos. (p. 42). Costa Rica: EDUCA.

Herrero, A. (2009). Monseñor Thiel en Costa Rica: visitas pastorales 1880-1901. Costa Rica: Editorial Tecnológica de Costa Rica.

Ibarra, E. (1999). Las manchas del jaguar: huellas indígenas en la historia de Costa Rica: Valle Central, siglos XVI-XX. Costa Rica: Editorial de la Universidad de Costa Rica.

Ibarra, E. (2002). Las sociedades cacicales de Costa Rica (siglo XVI). Costa Rica: Editorial de la Universidad de Costa Rica.

Instituto de Defensa del Café. (1935). Censo cafetalero. Provincia de San José. Cantón $18^{\circ}$ Curridabat. Revista del Instituto de Defensa del Café (Costa Rica) Tomo II. Pp. 321-344.

Instituto del Café de Costa Rica. (s.f.). Área cafetalera 2012, por región. (Tabla) Disponible en: http://www.icafe.go.cr/sector cafetalero/SIG/area cafetalera 2012 region.html.

Instituto del Café de Costa Rica. (s.f.). Área de café según región cafetalera. (Tabla) Disponible en: http://www.icafe.go.cr/sector_cafetalero/SIG/Area_region_cafetalera.html. 
Instituto Fomento y Asesoría Municipal. (1987) Atlas Cantonal de Costa Rica. Costa Rica: Imprenta Nacional.

Instituto Geográfico Nacional. (1991). Mapa de uso del suelo. Hoja Curridabat, escala 1:10 000. (Mapa). Costa Rica: Instituto Geográfico Nacional.

Instituto Nacional de Estadísticas y Censos. (s.f.). Censo 2011. Disponible en: http://www.inec. go.cr/Web/Home/GeneradorPagina.aspx.

Las fiestas patronales en Curridabat. (1961, 2 de julio) Eco Católico. Pp. 3-4.

Leandro, H. (1990). Antigua Iglesia de Curridabat. Boletín informativo. Costa Rica: Centro de investigación y conservación del Patrimonio Cultural 6 (1). p.4.

Leiva, A. (2008). Costa Rica en fotografías antiguas. Recopilación de libros I y II. Costa Rica: Jadine.

Levi, G. (1996). Sobre microhistoria. En: P. Burke et al. Formas de hacer historia. España: Alianza Editorial.

Madrigal, I. (1974). Apuntes para una monografía del Cantón de Curridabat. (Tesis de Licenciatura en Historia). Costa Rica: Universidad Nacional de Costa Rica.

Méndez, J. (2012). Bases conceptuales para comprender la importancia del territorio en la conformación de la identidad: el caso de San Rafael de Escazú. Revista de Ciencias Sociales, Vol. 137. Pp. 41-51.

Ministerio de Economía y Hacienda. Dirección General de Estadística y Censos. (1953). Censo Agropecuario de 1950. Costa Rica: Instituto Geográfico Nacional.

Molina, C. (2005). Y las mulas no durmieron: los arrieros en Costa Rica, siglos XVI al XIX. Costa Rica: Editorial de la Universidad Estatal a Distancia.

Molina, I. (2000). De la historia local a la historia social. Cuadernos Digitales: publicación electrónica en Historia, Archivística y Estudios Sociales, (3). pp. 1-5.

Municipalidad de Curridabat. (2003). Semblanza del cantón de Curridabat. Costa Rica: Dirección de Planeamiento Territorial. Municipalidad de Curridabat. 
Muñoz, F. (1990). Curridabat de rural a cosmopolita. En: Contrapunto, p. 62.

Muñoz, F. (2007). Curridabat anecdótico. Costa Rica: EDITORAMA. Pp. 3-4, 9.

Naranjo, C. (1997) La primera modernización de la caficultura costarricense (1890-1950). Revista de Historia, (36). Pp. 79-105.

Naranjo, C. (2007) Los sistemas de beneficiado del café costarricense: 1830-1914. Revista de Historia, (55-56). Pp. 39-71.

Obregón, C. (2000). El proceso electoral y el Poder Ejecutivo en Costa Rica: 1808-1998. Costa Rica: Editorial de la Universidad de Costa Rica.

Ornat, R. (s.f.). De indios desprestigiados al orgullo de ser indígena, 100\% costarricense: un análisis etnohistórico de una región huetar del valle central de Costa Rica. Disponible en: http:// hdrnet.org/461/1/Ornat_Clemente_Raquel.pdf.

Palmer, S. (2004). Sociedad anónima, cultura oficial: Inventando la Nación en Costa Rica. 18481900. En: Molina, I. y Palmer, S. Héroes al gusto y libros de moda. Sociedad y cambio cultural en Costa Rica (1750/1900). Costa Rica: Editorial de la Universidad Estatal a Distancia.

Peters, G. y Rojas, M. (2010). El censo cafetalero costarricense, 1935. (Proyecto de Investigación la Escuela de Historia). Costa Rica: Universidad Nacional de Costa Rica.

Peterson, A. (1952). Mapa de las regiones agrícolas de Costa Rica, Censo 1950. Costa Rica: Dirección General de Estadística y Censos.

Picado, M. y Quirós, J. (2006). Estudios historiográficos: Monseñor Víctor Manuel Sanabria. Costa Rica: Editorial de la Universidad Estatal a Distancia.

Pons, A. y Serna, J. (2004). Notas sobre la microhistoria. ¿No habrá llegado el momento de parar? Pasado y Memoria. Revista de Historia Contemporánea, (3). Pp. 6 y 15.

Portilla, O. (1979). Especial de Curridabat. Curridabat.p.7.

Poveda, E. (1997). Moral tradicional y religiosidad popular en Costa Rica (1880-1920). Costa Rica: Euroimpresora Sofía. 
República de Costa Rica. (1908). Anuario Estadístico (Anexo a la memoria de Fomento 19071908). Tomo undécimo. Costa Rica: Oficina Nacional de Estadística.

República de Costa Rica. (1958). Información general del problema actual de la lepra en nuestro país. Costa Rica: Talleres editoriales de Tipográfica Comercial.

Rodríguez, P. (1998). Historia del Cantón de Curridabat. Costa Rica: Mirembelli.

Rojas, A. (1997). La evolución de la agricultura costarricense en sus distintas épocas. Disponible en: http://www.mag.go.cr/acercadelmag/evolucion.html.

Rojas, G. (2000). Café, ambiente y sociedad en la cuenca del río Virilla, Costa Rica (1840-1955). Costa Rica: Editorial de la Universidad de Costa Rica.

Rojas, M., Samper, M. y Torres, M. (1994). Cambio técnico, ciclo laboral y productividad del trabajo en una empresa cafetalera costarricense, 1946-1961. Revista de Historia, (30). p. 107.

Salguero, M. (2007). Caminos y veredas de Costa Rica. Tomo I. Costa Rica: Editorial de la Universidad Estatal a Distancia.

Sánchez, J. (1995). Curriravá: historia de nuestras buenas fincas. E. Zeledón (Comp.) Costa Rica: Ministerio de Cultura, Juventud y Deportes, Dirección de publicaciones.

Sandí, J. (2011) La participación de la iglesia católica en el control del espacio en medio de la creación de un país llamado Costa Rica, 1850-1920. Revista de Historia, (63-64). p. 55 .

Siervas de los Corazones Traspasados de Jesús y María. (s.f.). Antonio de Padua. Disponible en: http://www.corazones.org/santos/antonio_padua.htm.

Solano, V. (s.f.). Monedas del Sanatorio Durán. Costa Rica: Sin editorial.

Suplemento Curridabat. (1989). La Prensa Libre. p. 4.

Thiel, B. (1983). Datos Cronológicos para la historia eclesiástica de Costa Rica. Costa Rica: Comisión nacional de Conmemoraciones Históricas.

Umaña, J. (2012). Ricardo Jiménez Oreamuno: el canciller. Costa Rica: Ministerio de Relaciones Exteriores y Culto, Instituto Manuel María de Peralta. 
Whiting, E. (1998). La historia desde una perspectiva geográfica. España: Editorial Espai/Temps.

\section{ACERCA DEL AUTOR}

Jorge Marchena Sanabria: Máster en Historia Aplicada con énfasis en Historia del Poder y Control Social de la Universidad Nacional. Docente de la Escuela de Historia, UNA. 


\section{Mapa 1}

CANTÓN DE CURRIDABAT

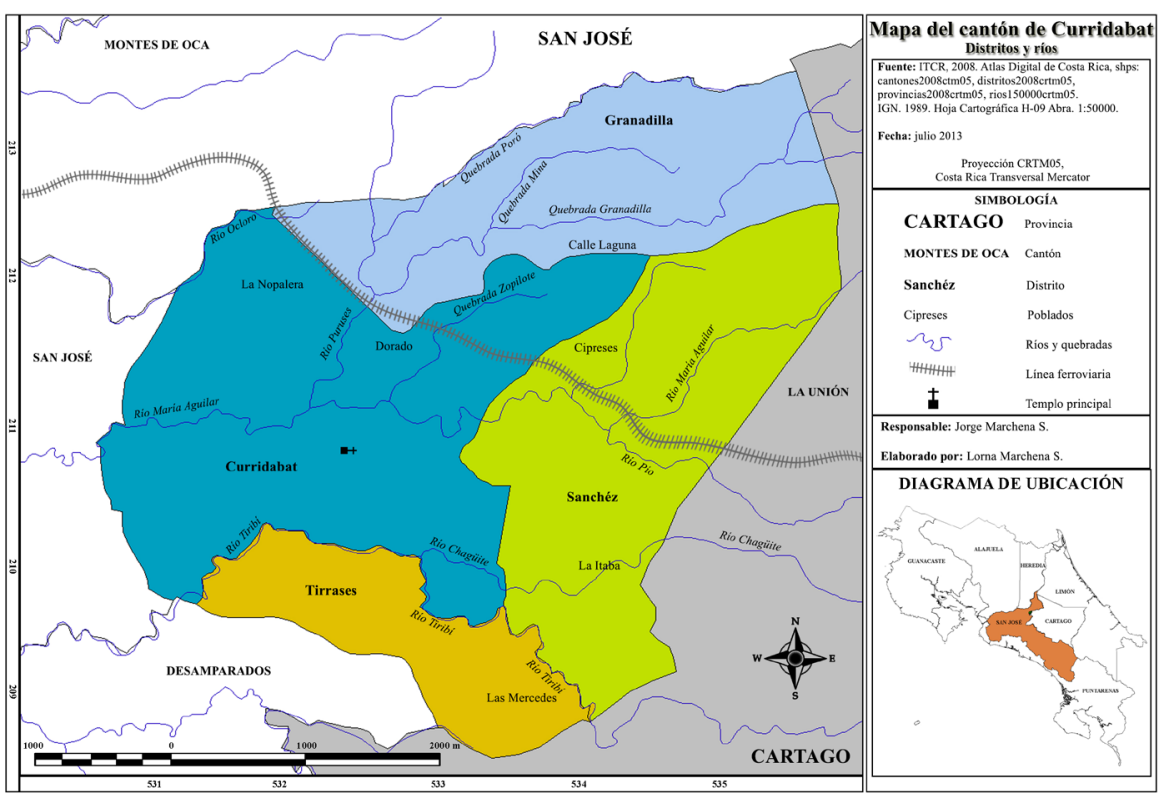


